\title{
Interfacial Chemistry in Steam-Based Thermal Recovery of Oil Sands Bitumen with Emphasis on Steam-Assisted Gravity Drainage and the Role of Chemical Additives
}

\author{
Spencer E. Taylor \\ Department of Chemistry, Centre for Petroleum and Surface Chemistry, University of Surrey, Guildford, \\ Surrey GU2 7XH, UK; s.taylor@surrey.ac.uk; Tel.: +44-1483-681-999
}

Received: 17 February 2018; Accepted: 26 March 2018; Published: 29 March 2018

\begin{abstract}
In this article, the importance of colloids and interfaces in thermal heavy oil or bitumen extraction methods is reviewed, with particular relevance to oil sands. It begins with a brief introduction to the chemical composition and surface chemistry of oil sands, as well as steam-based thermal recovery methods. This is followed by the specific consideration of steam-assisted gravity drainage (SAGD) from the perspective of the interfacial chemistry involved and factors responsible for the displacement of bitumen from reservoir mineral surfaces. Finally, the roles of the different chemical additives proposed to improve thermal recovery are considered in terms of their contributions to recovery mechanisms from interfacial and colloidal perspectives. Where appropriate, unpublished results from the author's laboratory have been used to illustrate the discussions.
\end{abstract}

Keywords: emulsions; heavy oil and bitumen; interfaces; oil sands; petroleum colloids; SAGD; surfactants; thermal recovery; wettability

\section{Introduction}

It is estimated that there are about 6 trillion barrels of oil stored in the form of heavy oil and bitumen [1]. One of the key characteristics of these unconventional crude oils is their very high viscosity at reservoir conditions. For example, typical Athabasca reservoir temperatures are about $7-11^{\circ} \mathrm{C}$ [2], and a typical Lloydminster reservoir temperature is about $25^{\circ} \mathrm{C}$ [3]. At these temperatures, the mobility of the oils is poor, with heavy oil viscosity being in the range of tens of Pa.s, whereas bitumen viscosity is in the range of hundreds of Pa.s [1]. Therefore, the recovery of these petroleum resources requires radically different strategies than those used for the more familiar conventional crude oils.

The approaches for heavy oil and bitumen production can be divided into thermal and non-thermal methods. The most widely used non-thermal methods include waterflooding, gas injection, and cold production, each of which has been thoroughly reviewed elsewhere [4].

Thermal recovery methods used in heavy oil production rely on significant viscosity reduction at increased temperatures [2]. These can also be divided into two classes based on the source of the heat: (i) hot-fluid injection in which the hot fluid (almost exclusively steam) is produced at the surface and injected into the reservoir; (ii) in situ heat-generation, in which the heat is generated in the reservoir, such as in situ combustion and fire-flooding [4].

Thermal (In Situ) Recovery of Bitumen Production from Oil Sands

Currently, there are two main steam-based thermal methods commercially used for recovering heavy oil/bitumen from oil sand reservoirs: cyclic steam stimulation (CSS) and steam-assisted gravity drainage (SAGD) [1]. 
CSS uses the same well (vertical, deviated, and horizontal) for steam injection and heavy oil production (Figure 1). In the first step, steam is injected with a pressure slightly greater than the fracturing pressure of the formation [1]. A soak period is then followed by production. This process is well-developed, and usually less than $20 \%$ of the original oil can be recovered [4]. The major drive mechanisms in CSS include formation re-compaction, solution-gas drive in early cycles and gravity drainage in later cycles [1]. The steam injection/production cycles are repeated until it is uneconomic to continue.

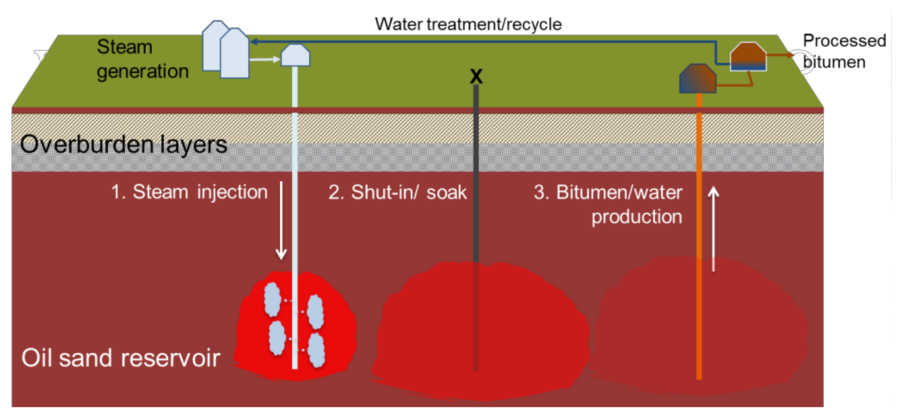

Figure 1. Schematic representation of a CSS operation using a vertical well for the three phases: steam injection, soak and production.

In SAGD, two parallel horizontal wells are used. Normally, steam at a sub-fracture pressure is injected via the injection well which is typically $5-10 \mathrm{~m}$ above the production well which is located close to the bottom of the reservoir (Figure 2) [2]. The major drive mechanism of SAGD is gravity drainage [1]. In practice, the SAGD process starts at a high steam pressure, which is reduced as the process evolves [2].
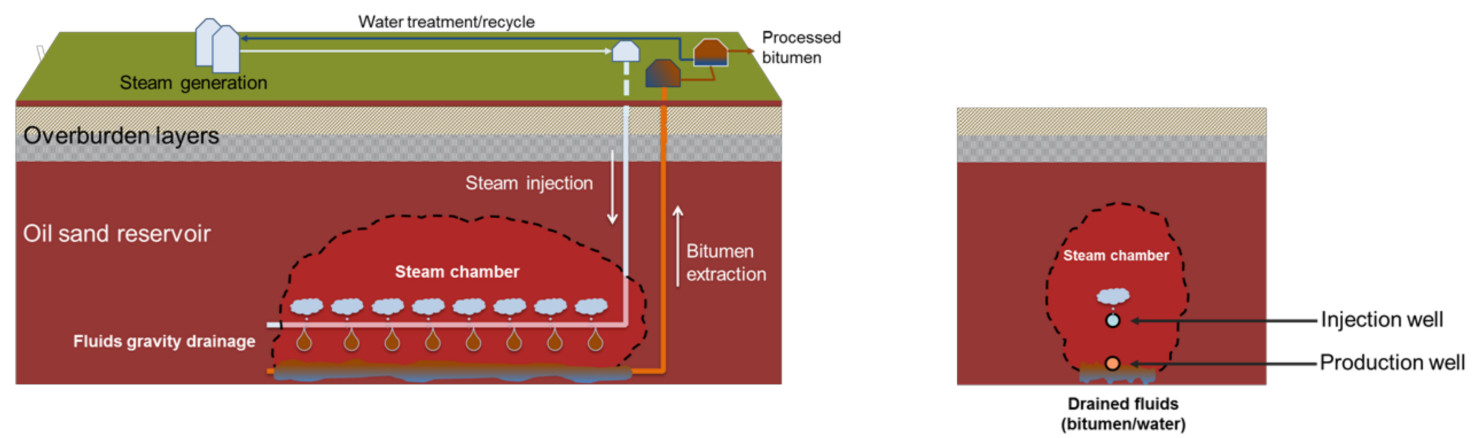

Figure 2. Schematic representation of a SAGD operation. Left: an illustration of the main elements of SAGD showing the juxtaposition of injection and production wells. Right: a cross-section view of the reservoir highlighting the shape of the steam chamber.

SAGD has been increasingly used for the production of bitumen from Canadian oil sands. Between 2004 and 2014 the production of bitumen using SAGD increased from 72 to 686 thousand barrels/day [5]. However, as reported in summer 2017, approximately 1.4 million barrels/day of bitumen were being produced by thermal in situ methods in Alberta alone. This number is projected to increase to 2.1 million barrels/day by 2030 [6].

Steam generation is an extremely energy-intensive process, which is usually provided by fossil fuel (e.g., natural gas, bitumen) combustion. Therefore, although steam injection offers robust bitumen recovery methods from reservoirs too deep for mining, there are continuing concerns over their high energy requirements and the environmental penalty caused by the associated release of carbon dioxide $\left(\mathrm{CO}_{2}\right)$. For example, the typical SAGD steam/oil ratio (SOR) in commercial operations will be in the range 2-10 [2] and it has been calculated that, for a typical high quality SAGD project operating at 
a SOR of 2.5 , approximately $20 \%$ of the bitumen produced is required to raise the steam (based on $80 \%$ conversion efficiency in the boiler) [7].

On this basis, it is clear that improvements in the efficiency of thermal recovery methods in terms of lowering energy requirements and $\mathrm{CO}_{2}$ release require increases in the SOR. To achieve this, an understanding of the interfacial chemistry associated with these recovery processes is needed in order to optimize oil release from reservoir mineral surfaces.

\section{Oil Sands Structure and Composition}

The presence of water has long been considered to be an integral part of oil sands structure, although there is some conjecture as to its exact nature. Early cryo-transmission electron microscopy (TEM) studies provided evidence that water in natural oil sands exists as a water-in-oil (w/o) emulsion [8]. On the other hand, a model of oil sands with a layer of water (approximately $10 \mathrm{~nm}$ thick) separating bitumen from the sand surface was subsequently proposed by Takamura [9]. This latter model was supported by calculations based on composition, pore radius, and surface areas of Athabasca (Canadian) oil sands, which concluded that such water films could exist with a thickness of 5-6 nm [10].

As far as bitumen composition is concerned, analyses based on infrared spectroscopy and elemental analysis of saturates, aromatics, resins, and asphaltenes (SARA) fractions, extracted sequentially from oil sands, suggested that these are not evenly distributed throughout the bitumen layers, with the most polar asphaltene and resin species being concentrated at the sand surfaces [11].

It is also necessary to consider that the oil composition may change during thermal production. When heavy oil or bitumen is produced with steam, for example, a common observation is that the produced oil is lighter than the original, which is believed to be a consequence of in situ upgrading processes [12-14]. It has been suggested [12,13] that minerals in the oil sands or the products of mineral-steam reactions [14] act to catalyze upgrading reactions (e.g., aquathermolysis [15-17]).

It is important to note that, other than the chemical compositions of the oils, to be discussed below, the size distributions of the solids and the wetting phase layer on their surfaces may also play important roles in fluid-fluid and fluid-solid interactions in oil sands. A comprehensive study has been reported very recently based on 42 sets of sandpacks using representative pore and rock configurations of the McMurray Formation, the primary oil sand resource in the world [18].

Compared with lighter, conventional oils, heavy oils and bitumen are enriched with hetero-species, some of which are active at liquid-liquid (oil/water) and/or solid-liquid (sand/oil or sand/water) interfaces. Among the many components present in the oils under consideration here are several classes which are interfacially-active, namely asphaltenes, naphthenic acids, and humic acids. In addition, as alluded to, fine particles can also influence important processes relevant to oilfield recovery and production. These classes are considered in more detail below.

\subsection{Asphaltenes}

Recognized as the heaviest and most polar components of crude oil, asphaltenes are defined as those oil components that are soluble in aromatic solvents but insoluble in $n$-alkanes. Asphaltene molecules become insoluble in the oil matrix (known as the 'maltenes') due to changes in maltene composition (and hence solvency) as a result of changes in pressure, temperature, etc. The compositions of asphaltenes differ according to the conditions used in their preparation. For example, higher carbon number $n$-alkanes normally lead to asphaltene precipitation at lower volume additions than their lower carbon number counterparts, but the corresponding asphaltene yields are reduced [19].

Asphaltenes have a tendency to form aggregates or clusters that influence their surface and interfacial activity and which, notwithstanding their compositional complexity, has been shown to be due to only a small proportion of the molecular species present [20].

Thus, it has been suggested that asphaltenes isolated using $n$-heptane are mixtures of two main fractions. One (designated A1) has a very low solubility in toluene $(\sim 90 \mathrm{mg} / \mathrm{L})$ while the other 
(designated A2) has a much higher solubility $(57 \mathrm{~g} / \mathrm{L})$. The strong tendency to aggregate is most likely due to the presence of the less soluble fraction which is present in larger quantities [20]. The adsorption of asphaltenes onto silica is an irreversible second-order adsorption, with the adsorption rate being strongly dependent on the asphaltene concentration: with increasing concentration, the effective adsorption rate decreases as concurrent asphaltene aggregation occurs [20]. Asphaltene adsorption on kaolinite also follows complex behavior [21,22] which has been related to the presence of asphaltene nanoaggregates in solution and agglomeration of the adsorbent particles [23].

Interfacial tension (IFT) studies have also revealed that asphaltene monomers and nanoaggregates have different adsorption kinetics at the oil/water interface [24]. The adsorption of asphaltenes at the toluene-water interface has been suggested to involve two steps, namely asphaltene monomer adsorption, followed by interfacial aggregation [25]. Further flocculation of asphaltene aggregates will lead to the formation of a three-dimensional network which acts as an effective barrier between oil and water. If the acidic fraction soluble in heptane (AFSH) isolated from the same crude oil is added, the interface is found to contain a mixed film containing AFSH and asphaltenes [25]. In this situation, the AFSH reduces the interfacial tension, while the presence of asphaltenes serves as a hydrophobic barrier between the two phases [25].

The status of asphaltenes in the oil is an important factor determining the stability of w/o emulsions. For example, it has been observed that asphaltenes exhibit the maximum capability of stabilizing w/o emulsions when they are close to their stability boundary [26], suggesting that asphaltene nanoaggregates or larger colloidal asphaltenes are more effective as emulsion stabilizers than asphaltene molecules. Increasing the asphaltene solvency or adding resins can reduce asphaltene surface activity and destabilize the emulsion $[27,28]$.

\subsection{Organic Acids}

In the petroleum industry, organic acids present in crude oils and oil products are termed naphthenic acids. Acids are present in almost all crude oils, with the amounts ranging from 0 to $3 \mathrm{wt} \%$ [29]. For Athabasca oil sand, the content of naphthenic acids in the bitumen is approximately $2 \mathrm{wt} \%$ [30].

Naphthenic acids are mixtures composed mainly of alkyl-substituted cycloaliphatic carboxylic acids and paraffinic (fatty) acids [29]. The carboxyl group is usually found on the side-chain rather than on the alicyclic ring [30]. As a result of these structures, organic acids have surfactant-like properties and play important roles in the interfacial chemistry of oil production. One study has revealed that the primary naphthenic acids are acidic species with molecular weights in the range $250-425 \mathrm{~g} / \mathrm{mol}$ and are most effective in reducing IFT [31]. In another study, the self-assembly behavior of the acidic species of bitumen and its distillate fractions was revealed using mass spectrometry [32]. It appeared that the lowest boiling distillate fraction $\left(375-400^{\circ} \mathrm{C}\right)$ showed the strongest tendency toward aggregation, occurring at concentrations as low as $0.05 \mathrm{mg} / \mathrm{mL}$ [32]. Compositional characterization revealed that the most abundant acidic species in the $375-400{ }^{\circ} \mathrm{C}$ distillation fraction are non-aromatic diprotic acids. On the other hand, the most abundant acidic species forming aggregates in the higher boiling $450-475{ }^{\circ} \mathrm{C}$ fraction are aromatic naphthenic acids [32].

Since asphaltenes and organic acids co-exist in crude oils, especially in bitumen, their combined effects on the stabilization of the oil/water interface needs to be considered. It was shown, for example, that naphthenic acids extracted from crude oils show greater IFT reduction in acid-free oil than in the aliphatic-aromatic solvent which is normally used as a model. This suggests that the interfacial properties are influenced by interactions occurring in the bulk oil phase between the naphthenic acids and asphaltenes [33]. A general mechanism is that the basic nitrogen-containing functional groups in asphaltenes interact with the naphthenic acids, leading to the formation of naphthenic acid-asphaltene complexes which have stronger capabilities of stabilizing the oil/water interface [31]. More recent studies have suggested that organic acids could soften the rigid asphaltene film on the oil/water interface and make the emulsion more stable [34]. 
The polar compounds enriched at the oil/water interface can be separated and characterized using various methods. For example, a "heavy water method" has been developed to isolate the interfacial materials, which contain a mixture of asphaltenes and carboxylic acid salts [35]. Compositional analysis of the interfacial materials using advanced characterization techniques such as high resolution mass spectrometry or 2D GC-MS, for example, has identified the enrichment of oxygen and oxygen/sulfur species at oil/water interfaces. It was also found that the unsaturation level and molecular size of the interfacial materials are important for their interfacial properties [36].

The adsorption of organic acids and asphaltenes has been observed to change the wettability of reservoir minerals, with potential impacts on oil production [37-40].

\subsection{Humic Acids}

There are significant amounts of toluene-insoluble organic matter (TIOM) in oil sands [41-45]. These materials are able to coat mineral surfaces to produce organic-rich solids (ORS). Generally, there are two types of ORS found in oil sands, a coarse fraction and an ultra-fine fraction. The coarser fraction usually is less than 44 microns and usually comprises aggregates containing humic matter and precipitated minerals. These heavy aggregates can carry associated bitumen into aqueous phases. On the other hand, the ultra-fine fraction contains clay particles with a major dimension of less than 0.3 microns. These clay particles are coated with organic matter, and remain associated with bitumen produced by the flotation method in surface mining processes [42].

Humic materials are able to form complexes with clays in various oil sands, bonded through Fe species [46,47]. Differences between complexes formed from oil sands of different origins is a result of differences in the distribution of the complexes in the oil sand solids. In caustic flooding, $\mathrm{NaOH}$ ionizes humic materials, leading to reductions in IFT and increasing oil recovery [47].

To identify the different solid fractions in oil sands, a cold water agitation test was developed by Kotlyar et al. [46]. Solids associated with bitumen were found to be enriched with humic matter, with the insoluble organic carbon content being as high as $36 \%$ and the solids containing a higher concentration of $\mathrm{Ti}, \mathrm{Zr}$, and Fe. Solids suspended in the aqueous phase had an insoluble organic carbon content of approximately $5 \%$, and were enriched with Al. The remaining solids showed a very low insoluble organic carbon content $(<0.3 \%) .{ }^{13} \mathrm{C}$ nuclear magnetic resonance spectroscopy indicated that the humic matter content of oil sands have a similar maturity as sub-bituminous coal [46]. However, elemental analysis suggested that the organic matter could have a different origin from most of the oil sands bitumen [48].

\subsection{Clays and Other Fines}

As mentioned in the previous section, fines/clay particles in natural oil sands could be coated with organic species, such as humic matter. During the SAGD process, these can become more oil-wet because of further deposition of asphaltenes. Oil-wet clay particles can stabilize the "rag layer" (comprising mainly w/o emulsions) invariably formed at oil/water interfaces during oil sand production [49]. Upon changing the wettability of these clay particles to water-wet, the emulsion is destabilized [50].

It is also possible that some polar compounds could partition into the water phase during the SAGD process. In turn, polar organic compounds dissolved in the SAGD produced water could play an important role in the interaction between the bitumen and water during SAGD production. One group of the possible polar organics in SAGD water are the humic acids discussed above, which can lead to humic acid-clay complex formation in oil sands $[46,47]$. Fluorescence excitation-emission matrix spectroscopy (FEEMS [51]) characterization of SAGD-produced water confirmed the existence of humic acids and the related fulvic acids [52]. A systematic characterization revealed that naphthenic acids and larger carboxylic acids are present in SAGD produced water, the major acidic species containing 2-3 rings [53]. 


\section{Nature of Steam-Based Thermal Recovery, Especially SAGD and Its Variants}

Conceived and developed by Butler and his coworkers at Imperial Oil in the late 1970s, SAGD is the most widely-used steam-based in situ heavy oil/bitumen recovery method currently available [54]. The original SAGD concept was aimed at improving recovery using gravity as the major driving force involved in separating the oil from the reservoir matrix. Compared with conventional steam drive processes, it was envisaged that this also avoids excessively cooling the produced fluids.

The underlying principle of SAGD involves the continuous introduction of steam into a reservoir via a perforated horizontal well at temperatures of typically $150-250{ }^{\circ} \mathrm{C}$ at pressures which depend on the nature of the oil and the formation. As can be seen in Figure 2, the steam permeates upwards and outwards through the formation creating a so-called steam chamber. This reduces the contacted oil viscosity considerably, which is then carried with the steam and condensed water to the cooler growing extremities of the chamber, where the liquids then drain under gravity. These then collect below the steam inlet level where they are extracted via a second horizontal production well a few meters below the injection well. Early work indicated that recovery rates of $79-159 \mathrm{~m}^{3} /$ day can be achieved, with bitumen recoveries of the order of $50 \%[1,55,56]$. SAGD is deemed suitable for unconsolidated reservoirs with high vertical permeability, and is therefore relevant to oil sand deposits for which it is a more environmentally acceptable alternative than mining.

This relatively simple scheme, however, hides many complexities, and the understanding of the mechanics of steam chamber development and heavy oil/bitumen production rates remain at a relatively early stage. For example, Al Bahlani and Babadagli reviewed the status of SAGD based on laboratory experimental studies and highlighted various features of the process that contribute to the process and for which a more detailed understanding is necessary [57]. The areas identified included: steam chamber development, resulting from the low density steam penetrating the formation above it; steam fingering theory, since steam rising through the developing chamber occurs irregularly, and not as a uniform front [58]; co-current and counter-current displacement, reflecting the complexity of the fluid flows occurring during SAGD, one consequence of which can be the formation of a w/o emulsion through condensation of steam in the oil; and heat transfer and distribution through the steam chamber, which is critical to providing a full understanding of the process.

Without recourse to a full appreciation of SAGD theory, several alternative variant strategies have nevertheless been identified to improve factors such as the efficiency of heat transfer, steam chamber reach, and bitumen removal. Al Bahlani and Babadagli classify these variants as chemical and geometrical [57]. Included among those based on chemical additives were: (i) the use of light solvents, either as hybrid processes by introducing the solvent with the steam, or using solvent vapor to completely replace the steam (the Vapex process [59]); and (ii) the introduction of gas and surfactants to generate foams. Thus, expanding solvent-SAGD (ES-SAGD) is one development based on the addition of low levels of solvent (e.g., hexane), which co-condenses at the cooler extremities of the steam chamber, and acts to reduce the viscosity of the mobilized bitumen. Foam-assisted (FA)-SAGD has been proposed by Chen [60] and tested using two-dimensional reservoir simulation models. The use of foam was shown to have an overall positive impact on the energy efficiency of the process, compared with SAGD alone, through controlling steam breakthrough in the inter-well region. One negative effect of the introduction of foaming steam into the simulation, however, was a reduction in the steam mobility in the upper regions of the chamber, which had a consequent negative impact on recovery rates.

SAGD operations are also potentially demanding in terms of water recycling. Treatment of produced water for re-use in steam generation, for example, is an essential part of sustainable water recovery operations [61]. The chemistry associated with SAGD operations can make this challenging, however, owing to the significant dissolution of reservoir minerals—e.g., silica—which increases substantially at temperatures above $100^{\circ} \mathrm{C}$. In turn, this increases the probability of silicate mineral deposition occurring on susceptible surfaces [62]. In the case of silica, solubility is greatly 
enhanced under high $\mathrm{pH}$ conditions, although by taking appropriate measures steam production is not necessarily compromised [63], as discussed in Section 5.

\subsection{Factors Affecting SAGD Performance}

In addition to the factors discussed above, there are many others that are considered to affect SAGD recovery rates, including the heterogeneity and permeability of the reservoir [64], influencing both propagation of the steam chamber and non-uniform heat transfer through the formation, as well as phenomena such as steam fingering and viscous coupling (related to emulsion formation) involving the steam (water) and oil phases. The latter factor exemplifies one of the most important aspects of any scheme based on gravity drainage, that of the viscosity of the draining fluid. This is evident from the various mathematical treatments based on Butler's original SAGD concept for the rate of oil production, $q$, which have been further developed in the intervening years, but the basic form is [65]

$$
q=L \sqrt{\frac{B \phi \Delta S_{0} k g \alpha h}{m v_{s}}}
$$

In Equation (1), $L$ is the length of the production well, $\varphi$ is the porosity of the reservoir, $\Delta S_{0}$ is the difference between initial and residual oil saturation levels, $k$ is the effective oil permeability, $\alpha$ is the thermal rock diffusivity, $h$ is the height of the steam chamber, $v_{s}$ is the kinematic oil viscosity under the reservoir conditions, $m$ is a constant relating to the temperature dependence of viscosity, and $B$ is a constant relating to the system configuration.

Some parameters in Equation (1) are characteristics of the reservoir and are hence very difficult to influence. It is also evident that the drainage (hence recovery) rate is proportional to (viscosity) $)^{-0.5}$, and therefore minimizing oil viscosity is an obvious but key factor in optimizing the SAGD process. Positive effects can also be envisaged, however, both by minimizing residual oil saturation and increasing the porosity; these properties are related to the effectiveness of oil removal from the porous structure. Associated with these properties will be the size of the steam chamber, since more efficient displacement of oil will lead to improved steam chamber propagation.

As mentioned above, heavy oils and bitumen exhibit a natural tendency to form $\mathrm{w} / \mathrm{o}$ emulsions owing to the presence of natural surfactants present in the oil phase, possibly also favored by the viscosity ratio between oil and water. Therefore, flow rate restrictions could be expected to arise from the in situ formation of $\mathrm{w} / \mathrm{o}$ emulsions, since these will be more viscous than the heavy oil or bitumen at any given temperature. The viscosity of emulsions is highly dependent on the dispersed water phase content (volume fraction, $\phi$ ), according to empirical relationships, such as that given by Krieger and Dougherty $[66,67]$, given in Equation (2).

$$
\eta=\eta_{0}\left(1-\frac{\phi}{\phi_{\max }}\right)^{-2.5 \phi_{\max }}
$$

In Equation (2), $\eta_{0}$ and $\phi_{\max }$ are the (shear) viscosity of the oil phase and the maximum close-packed phase volume, respectively, and the factor 2.5 is the intrinsic viscosity for spheres. This equation indicates, for example, that the incorporation of $10 \%$ dispersed water phase (by volume) will result in approximately 30\% increase in viscosity, and for 30\% water incorporation, the viscosity is expected to increase by approximately $160 \%$ (calculations assuming that $\phi_{\max }=0.74$, the maximum packing fraction for monodisperse spherical droplets, although it is often found that this value may be significantly different, which will affect the quoted increases in viscosity).

However, from the point of view of gravity drainage, intermixing of steam, condensed water, and bitumen under conditions of high temperature, pressure and shear, as well as a water/bitumen ratio of at least 3 at the extremities of the steam chamber provides extremely favorable conditions for bitumen emulsification in water to take place. In fact, produced fluids are found to comprise mixed water-in-oil and oil-in-water $(\mathrm{w} / \mathrm{o}+\mathrm{o} / \mathrm{w})$ and multiple (principally water-in-oil-in-water 
$(\mathrm{w} / \mathrm{o} / \mathrm{w})[61])$ emulsions. From the standpoint of production efficiency, formation of $\mathrm{o} / \mathrm{w}$ emulsions may be considered to be more beneficial, since these will invariably have lower viscosities and potentially drain more efficiently than the corresponding w/o emulsions. As an example, Figure 3 shows the main produced emulsions (o/w and w/o) from an Athabasca oil sands SAGD operation in which both bitumen and water droplet sizes are seen to be less than 20 microns, as described previously [68]; many are seen to be considerably less than 5 microns for both emulsion types. Higher magnification $\mathrm{o} / \mathrm{w}$ emulsion images than are shown here indicate that the bitumen droplets contain inclusions of finely dispersed water droplets (i.e., w/o/w), consistent with operational experience [61]. In practical terms, however, these examples can only be considered as being a snapshot of the fluids produced at a moment in the operational history, since the predominant emulsion types in SAGD will be influenced by the water/bitumen ratio, which will vary over the production lifetime of the operation.

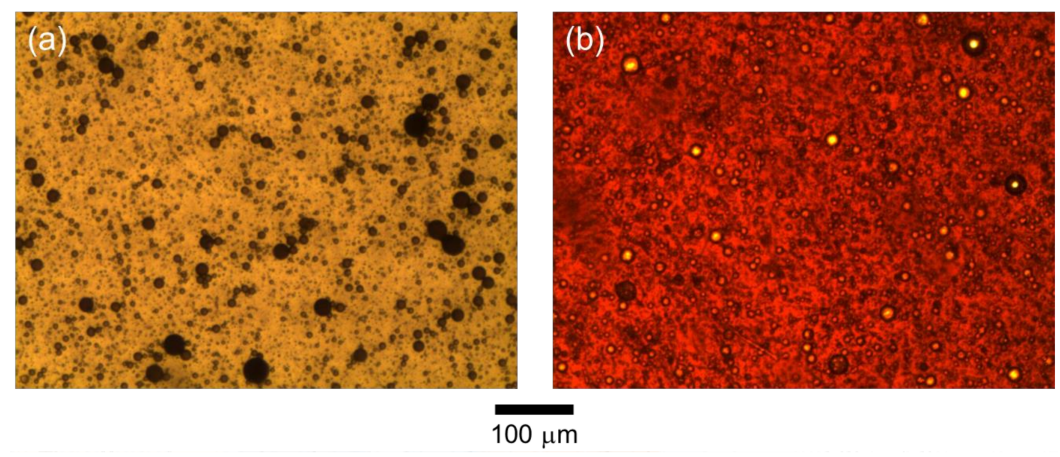

Figure 3. Examples of photomicrographs of emulsions produced from a SAGD process. (a) Oil-in-water emulsion; (b) Water-in-oil emulsion comprising the bulk bitumen phase. Unpublished work from the author's laboratory.

Emulsions of this type have also been encountered in produced fluids from steamfloods incorporating chemical additives. Thus, Sarbar et al. investigated the effect of surfactant (sodium dodecyl benzene sulfonate) and alkaline $(\mathrm{NaOH})$ solutions on the flow of $\mathrm{o} / \mathrm{w}$ emulsions through porous media [69]. Some instability of the emulsions was apparent, as it was found that $10 \% \mathrm{o} / \mathrm{w}$ emulsions were transported through a $100 \mathrm{~m}$ length of porous media (unconsolidated sandpack), with only around $70 \%$ of the emulsion remaining intact. Increasing the oil content of the emulsion increased the pressure drop across the porous media, in accordance with the increasing viscosity (Equation (2)), but also possibly reflecting a reduction in stability (through inversion) of the $\mathrm{o} / \mathrm{w}$ emulsion.

Arguably, o/w emulsions are favored during pre-production in the reservoir; however, in post-production they can potentially pose some operational problems requiring specific chemical treatments [70].

\subsection{Oil Mobilization Mechanisms in SAGD Processes}

As described above, the basis of SAGD is the formation of a hot, oil-depleted zone in the reservoir by the horizontal introduction of superheated steam. The resulting steam chamber produced grows as the steam gives up its latent heat to the reservoir rocks and the oil, which drains under gravity together with condensed water. During the growth of the steam chamber, various mechanisms play a part in mobilizing the oil and affecting recovery rates, including:

- Solvency/dissolution (e.g., using oil-miscible solvents)

- Emulsification

- Displacement/detergency

- Foam formation 
The various interactions between steam (and any additional components), oil and the reservoir mineralogy determine the efficiency and extent of steam chamber growth, oil displacement, and ultimately potential recovery rates (some aspects of which are broadly expressed by Equation (1)). In the absence of additional steam components, significant residual oil is left behind in the steam chamber (up to $50 \%$ recoveries have been quoted, e.g., [1,55,56]), and water is incorporated into the recovered oil.

This suggests that there should be sufficient scope for improvements to be made in respect of reducing residual oil saturation and improving overall oil recovery. For example, the inclusion of suitable solvents to steam would lead to improved oil mobilization through improved drainage arising from lower oil viscosities, but perhaps would not restrict the formation of $\mathrm{w} / \mathrm{o}$ emulsions. On the other hand, inclusion of low concentrations of chemical demulsifiers would alleviate the formation of w/o emulsions, without necessarily enhancing overall recovery. Displacement mechanisms, for example involving surface-active agents, would address overall recoveries, reducing residual oil saturations, and the nature of the agents involved would also reduce the tendency for w/o emulsion formation, preferring instead to stabilize o/w emulsions.

Not all of the above mechanisms would necessarily apply to all SAGD situations, but their consideration is relevant in attempts to improve the efficiency of SAGD processes.

\subsubsection{What Happens at the Liquid/Liquid Interface? Water-in-Oil Emulsions}

When steam is injected into oil sands, water-in-bitumen emulsions have a natural tendency to form from the condensed water [68,71]. By co-injecting water and bitumen into sandpacks, Chen et al. [71] demonstrated the importance of the wettability of the porous medium and the water flow rate; oil-wet media favored $\mathrm{w} / \mathrm{o}$ emulsification and the extent of emulsification increased as the water flow rate was increased [72].

As alluded to above, the formation of w/o emulsions is commonly observed during steam-based thermal recovery. Although some benefit of $\mathrm{w} / \mathrm{o}$ emulsion formation may accrue under certain circumstances, such as from plugging unproductive high permeability zones [73], there is a greater concern of the increased viscosity of the $\mathrm{w} / \mathrm{o}$ emulsion on production. However, based on an analysis of production data from a CSS operation in Cold Lake (AB, Canada), Vittoratos proposed that improved permeability arises from the formation of water-in-bitumen emulsions through greater effective bitumen occupancy of the pore spaces [74]. It was assumed that the increased emulsion viscosity is "more than compensated for by the increased relative permeability to oil resulting from increased bitumen saturation due to swelling" [74]. Currently, most operational SAGD projects are at relatively early stages where the bitumen saturation is still high. However, when the bitumen saturation decreases below a critical value, the SAGD process may become uneconomic, making alternative recovery methods necessary in future.

Related to the foregoing, the involvement of asphaltenes in the respective stabilities of heavy and conventional oil emulsions under high temperature conditions has been the subject of a recent study [75] in which it was shown that water emulsification in a heavy oil increases with increasing temperature (studied up to $200^{\circ} \mathrm{C}$ ), accompanied by increased stability and higher viscosity of the resultant emulsions. By contrast, the opposite trend was found for a conventional oil [75]. The authors considered a mechanism for heavy oils involving asphaltene disaggregation leading to a greater number of asphaltene molecules available to stabilize the oil/water interfaces [75]. However, it has also to be considered that the viscosity increase can be counteracted to some extent by a dilution effect of higher concentrations of dissolved water at the high temperatures [76,77], leading to significant viscosity reductions at SAGD temperatures, e.g., approximately $20 \%$ reduction seen at $200{ }^{\circ} \mathrm{C}$ [77].

Chung and Butler concluded that the primary mechanism for the in situ formation of w/o emulsions during SAGD is condensation of steam in contact with bitumen, with the condensing water effectively being engulfed by spreading oil films [71]. "Precursor" oil films that preferentially spread from bitumen over a water surface were studied by Drelich et al. more than 20 years ago [78] and 
have recently been shown [79] to contain a range of polar surface-active components, which could therefore explain water uptake by the oil by this mechanism. However, a second mechanism involves counter-current flow of steam and oil within the steam chamber. The result is that water droplets with diameters in the range 10-20 $\mu \mathrm{m}$ are uniformly distributed throughout the oil phase (see also Figure $3 \mathrm{~b}$ ). In arriving at these conclusions, these authors also determined that emulsification (measured in terms of the emulsified water/oil ratio) was not significantly affected by the quality of steam used in their experiments, the porosity of the reservoir, or the injection steam pressure. On the other hand, less water was emulsified (approximately $10 \%$ versus $20 \%$ ) if the formation initially contained $12.5 \%$ connate water. More recently, emulsification of water at the steam/oil interface was proposed by Azom and Srinivasan to facilitate convective thermal transfer, thereby leading to improved recovery, and suggesting that such a mechanism could explain the underestimation of recovery rates given by some SAGD models [80].

Visualization of the process of emulsion formation at the steam chamber interface using scaled two-dimensional reservoir models containing porous packing materials has been reported by Sasaki et al. [81]. Fine water droplets of the order of $10 \mu \mathrm{m}$ were observed to form at the interface between steam and heavy oil phases. The droplets were then incorporated into the flowing oil phase. The recovered fluids from the model comprised condensed water and w/o emulsion phases [81], as shown schematically in Figure 4 with the proposed change in the wettability of the reservoir either side of the steam front being indicated. Incomplete removal of oil from the mineral surfaces will modify the original oil-wet characteristics, most likely resulting in a mixed-wet condition behind the steam/condensed water front. Ahead of the front, mobilization of the oil together with water entrainment are shown.

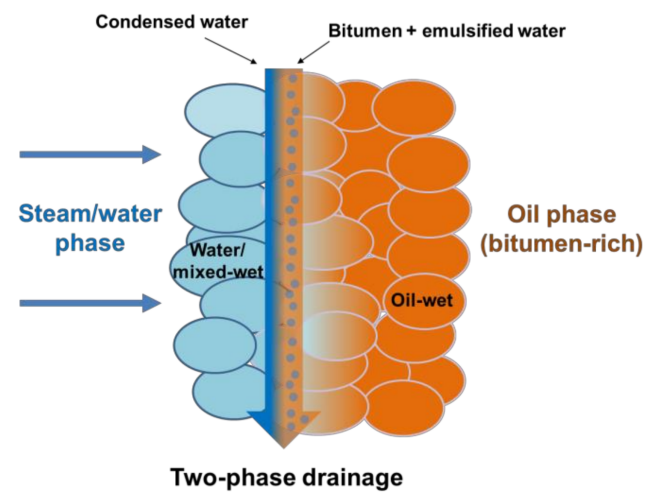

Figure 4. Schematic of drainage and the formation of w/o emulsions at the steam chamber walls (modified from Sasaki et al. [81]).

\subsubsection{What Happens at the Solid/Liquid Interface? Displacement/Detergency/Wetting}

As mentioned earlier, Equation (1) indicates that a reduction in oil saturation will lead to an improvement in recovery rate. Although not necessarily a primary consideration for improving SAGD efficiency, more effective oil separation from reservoir surfaces could be brought about by the classic roll-up detergency mechanism (see below). This occurs through bitumen de-wetting the solid surface and is caused by a reduction of water/solid and water/bitumen interfacial tensions, with a consequent increase in the contact angle $\theta$ between the bitumen and solid. This is depicted in Figure 5 for the equilibrium contact between bitumen and a solid surface surrounded by water. Interfacial tensions (energies) are indicated between the different pairs of phases. By considering the balance of forces at the three-phase contact point, this criterion is met if the water/solid and water/bitumen interfacial tensions are reduced—usually arising upon the addition of a suitable surfactant. 
Young's equation for the situation shown in Figure 5 is given by

$$
\gamma_{\text {solid } / \text { water }}=\gamma_{\text {solid } / \text { bitumen }}+\gamma_{\text {water } / \text { bitumen }} \cos \theta
$$

so that if the surfactant reduces both $\gamma_{\text {solid/water }}$ and $\gamma_{\text {water/bitumen }}$ then $\cos \theta$ will change according to

$$
\cos \theta=\frac{\gamma_{\text {solid } / \text { water }}-\gamma_{\text {solid } / \text { bitumen }}}{\gamma_{\text {water }} / \text { bitumen }}
$$

Since $\gamma_{\text {water/bitumen }}$ will generally be affected to a greater extent than $\gamma_{\text {solid/water }}, \theta$ will show a tendency to increase, resulting in release of the oil from the surface, consistent with classical detergency theory. Using the same considerations, interfacial displacement by thin film spreading agents (TFSAs, see later) would lead to similar recovery improvements.

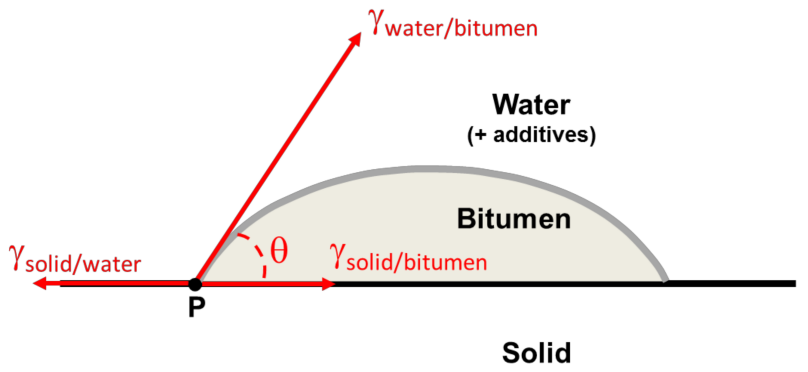

Figure 5. Schematic depiction of the three-phase contact point $P$ involving a bitumen drop on a solid surface surrounded by an aqueous additive solution.

The effect of steam alone has also been demonstrated to improve permeability. A limestone core with permeability impaired as a result of asphaltene deposition was treated using steam $\left(\right.$ at $\left.263^{\circ} \mathrm{C}\right)$, which improved the core permeability by an average approximately 95\% [82]. A similar result was reported for steam treatment in an Oman field [83].

Surface modification has also been shown to give promising results for oil recovery in laboratory and field tests [84]. Contact angle measurements showed that deposition of fine calcium carbonate $\left(\mathrm{CaCO}_{3}\right)$ particles on sand substantially increased water-wettability, and subsequent laboratory corefloods demonstrated that $\mathrm{CaCO}_{3}$ deposition improved oil recovery. This approach was then trialed in a CSS field test at Elk Point in Alberta, Canada. Oil production (both oil cut and oil rate) had declined over four cycles (see Figure 2) from $87 \mathrm{vol} \%$ oil at $30.7 \mathrm{~m}^{3} /$ day to $17 \mathrm{vol} \%$ oil at $3.6 \mathrm{~m}^{3} /$ day, which was believed to be a result of decreasing water wettability [84]. Therefore, prior to the fifth cycle, the near-wellbore region was treated by deposition of a thin layer of $\mathrm{CaCO}_{3}$ particles. This resulted in an increase in oil cut and oil rate (23 vol \% and $8.2 \mathrm{~m}^{3} /$ day, respectively), and a corresponding reduction in steam/oil ratio (from 22.9 to 8.5 ) [84].

On the other hand, in a SAGD process, changing the wettability around the production well from water-wet to oil-wet was shown to enhance bitumen recovery [85]. Laboratory experiments and numerical simulation suggested that such a wettability change can reduce the fluid communication time (between injection and production wells), and increase the bitumen production rate, at least during the early stages of production [85]. An oil-wet production well zone can also partially prevent water production. Additionally, the simulation study also suggested that it may not be advantageous to maintain an oil-wet production zone during the full production period [86].

On the basis of these examples, it is evident that different impacts of wettability on steam-based thermal recovery seem to be dependent on, e.g., the thermal production method (SAGD versus CSS), stage of production (early stage, plateau stage or late stage), etc. In CSS, the steam injection and oil/water production is via the same well. For SAGD, the steam is injected via an injection well while the oil is produced from a separate production well. 
Increasing the $\mathrm{pH}$ can reduce bitumen-rock interactions. Thus, for example, a certain $\mathrm{pH}$ can be reached where bitumen still adheres to the rock surface, but the low contact angle of the original bitumen on the surface increases to form drops, as exemplified in Figure 6 which shows the roll-up of bitumen on sand. The sequence shown in Figure 6 shows the bitumen gradually (over a period of several minutes) dewetting the sand surface $(\mathrm{a} \rightarrow \mathrm{d})$ and eventually being liberated as droplets. This has been the main principle underlying flotation treatment used in bitumen recovery from mined oil sands. In the case of alkali treatment, it has been found that the type of alkali used during this process is important. Thus, Flury et al. [87] found that ammonium hydroxide $\left(\mathrm{NH}_{4} \mathrm{OH}\right)$, although a weak base, is remarkably more effective than sodium hydroxide (caustic soda; $\mathrm{NaOH}$ ) in separating bitumen from the rock. This was ascribed to a more hydrophobic surface being generated with $\mathrm{NH}_{4} \mathrm{OH}$, as well as a lower (negative) zeta potential of bitumen due to the release of lower concentrations of natural surfactants [87].

(a)

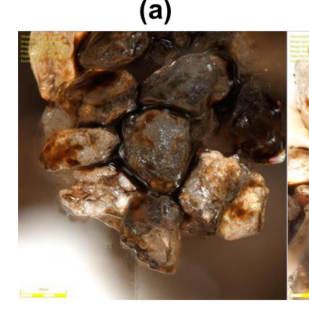

(b)

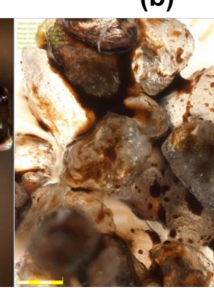

(c)

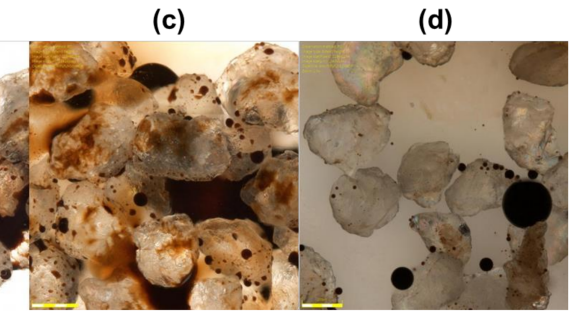

Figure 6. Sequence (a-d) of images showing roll-up and detachment of bitumen coating on sand (bars represent 200 microns). This effect can be brought about in a number of different ways, including chemical addition and $\mathrm{pH}$ change. Unpublished images from the author's laboratory.

\section{Chemical Additives in Steam-Based Thermal Recovery}

Over the years, several types of additive have been evaluated in conjunction with steam to try to improve oil recovery. Different mechanisms are applicable to each of these which are summarized in Table 1.

Table 1. Summary of additive classes and relevant recovery mechanisms.

\begin{tabular}{ll}
\hline Additive Type & Mechanisms \\
\hline Solvents & Dissolution of oil; viscosity reduction \\
\hline Alkaline agents & $\begin{array}{l}\text { Interfacial tension reduction by activating indigenous surface active oil } \\
\text { components; displacement and emulsification of oil droplets }\end{array}$ \\
\hline \multirow{3}{*}{ Surfactants } & $\begin{array}{l}\text { Foaming-steam (and non-condensable gas) mobility control Interfacial } \\
\text { tension reduction-oil displacement by surface dewetting, followed by } \\
\text { emulsification of oil droplets }\end{array}$ \\
& $\begin{array}{l}\text { Oil displacement by microemulsion formation } \\
\text { Oil displacement by thin-film spreading agents } \\
\text { Demulsification of w/o emulsions }\end{array}$ \\
\hline \multirow{2}{*}{ Nanoparticles } & $\begin{array}{l}\text { Enhanced spreading and wettability modification } \\
\text { Interfacial tension reduction }\end{array}$ \\
& Oil upgrading (catalytic nanoparticles) leading to viscosity reduction \\
\hline
\end{tabular}

The earliest uses of additives in conjunction with steam, ranging from the late 1960s through to the early 1990s, were concerned with reducing the propensity for w/o emulsions to be formed; the application of ppm concentrations of chemical demulsifiers was shown to be beneficial in this respect and led to increased production and reduced post-production treatment. Castanier and Brigham [88] summarized data from 16 field tests involving the use of additives to improve steam-based recovery during the 1980s. There was a reasonable amount of activity during this period, and overall, the inclusion of additives was positive. CSS operations used alkali and TFSAs, with surfactants 
being used in steam drives and cyclic applications and injected continuously, in slugs or cyclically. The mechanisms considered to be applicable in these cases include:

- Detergency, including dissolution of asphaltenes, reducing oil/water interfacial tension, and modification of the wetting characteristics of the rock.

- Foam-assisted diversion of the steam to unswept areas of the reservoir.

Castanier and Brigham also made the point that both types of mechanism could be combined to optimize recovery [88], although no tests had been conducted at that time (or hitherto, to the present author's knowledge) to test that suggestion. Almost exclusively, sulfonate surfactants from various sources were used. The use of alkali also appeared to be successful.

Shedid and Abbas considered the recovery of Egyptian heavy oil using vertically [89] and horizontally [90] configured steamflooding in laboratory sandpacks. The effects of alkali and nonionic surfactant (Triton X-100, an ethoxylated octyl phenol) were found to be very similar under the experimental conditions, although the combination of alkali and surfactant was found to be most effective in enhancing the overall recovery [89].

Yamazaki et al. used a laboratory rig to evaluate the use of steam in conjunction with solvents or alkali to enhance recovery from Athabasca oil sand at temperatures up to $200{ }^{\circ} \mathrm{C}$ [91]. The injection of solvents with steam was found to improve bitumen recovery, with benzene producing the best effect. The addition of sodium silicate (an alkaline agent, used at $2000 \mathrm{ppm}$ ) improved recovery over steam alone, and it also lowered the extraction temperature (from $90{ }^{\circ} \mathrm{C}$ in the case of pure steam to $70{ }^{\circ} \mathrm{C}$ ). These effects might be a consequence of a reduction in interfacial tension. In more recent studies using alkaline flooding alone, Madhaven and Mamora obtained improved recovery of Duri heavy oil compared with San Ardo [92]. Significantly, the interfacial tensions of the respective oils measured against $5 \mathrm{wt} \%$ sodium hydroxide solution were 9.5 and $26.5 \mathrm{mN} / \mathrm{m}$, to be compared with approximately $0.04 \mathrm{mN} / \mathrm{m}$ reported by Abbas and Shedid [90]; the incremental oil recoveries found by the former workers therefore appear to indicate that a significant reduction in interfacial tension is necessary to improve recovery.

Simple nitrogen-containing compounds were previously utilized by Brown et al., for which they were considered to act as interfacial tension reducers [93]. Introduction of aqueous solutions of a number of these compounds into the steam flow-line was shown to have a beneficial effect on recovery when used in conjunction with alkaline solutions. Thus, compounds such as nitroanisole and various pyridines and quinolines were shown to lead to improvements. However, in the only specific example given, the use of quinoline in aqueous $0.02 \mathrm{~mol} / \mathrm{L}$ sodium hydroxide was compared with steam only, thereby not unequivocally accounting for the possibility of additional effects arising from the alkaline conditions. No explanation or mechanism for the behavior was proposed, nor comments made regarding the additive stability under the test conditions. In other studies, however, it has been shown that pyridine and quinoline are stable in pure water under aquathermolysis conditions [94], but it is possible that they will be more reactive under alkaline conditions, thereby generating other species that could be involved mechanistically.

Many steam-based enhanced recovery approaches suffer from conformance problems resulting from the oil-bearing regions being bypassed as a result of gravity segregation and viscous fingering. Steam sweep efficiency can be improved by the introduction of more viscous foams [95].

Recognizing that the oil can affect foam stability (e.g., see [60]), Dilgren and Owens evaluated various olefin sulfonates for their ability to sustain steam-containing foams and thereby aid oil recovery by flowing steam and non-condensable gas vertically upward through a sandpack [96]. Pressure drops recorded in the sandpack increased substantially, indicative of the influence of foam, with preferred steam foam-forming compositions comprising specific olefin sulfonates and electrolyte.

Maini and Ma conducted some of the most comprehensive evaluations of the stability of foams at high temperatures and pressures, as well as determining the corresponding thermal stability of the surfactants [97]. Novosad et al. considered adsorption losses to sand of two of the contemporary 
candidate foam-producing surfactants available at the time (1980s) that were previously shown to be thermally stable [98]. Results obtained at $50-150{ }^{\circ} \mathrm{C}$ indicated that losses through adsorption on sand were relatively low $(<1 \mathrm{mg} / \mathrm{g})$.

\subsection{The Emerging Role of Nanotechnology}

In recent years, the role of nanotechnology in enhancing oil recovery has been given serious consideration. The review articles by Cheraghian and Hendraningrat [99,100], Negin et al. [101] and Hashemi et al. [102] provide appropriate background as far as the present discussion is concerned. Most specifically, however, in the context of heavy oil and bitumen recovery, the application of a relatively new group of additives based on colloidally-dispersed inorganic oxide nanoparticles, known as nanofluids, is currently being explored. The dispersed nanoparticles exhibit solid-like ordering at the edge of the spreading fluid [103] as well as affecting the wettability of solids [104,105] and reducing oil/water interfacial tension [105], making them potential candidates for the displacement of oil from surfaces [106]. This occurs as a result of a disjoining pressure being created by the build-up of a nanoparticle wedge between the oil and the solid surface [104], as shown in Figure 7. Shrinkage of the oil/solid contact line on a microscopic level effectively increases the macroscopic contact angle, thereby displacing the oil from the surface.

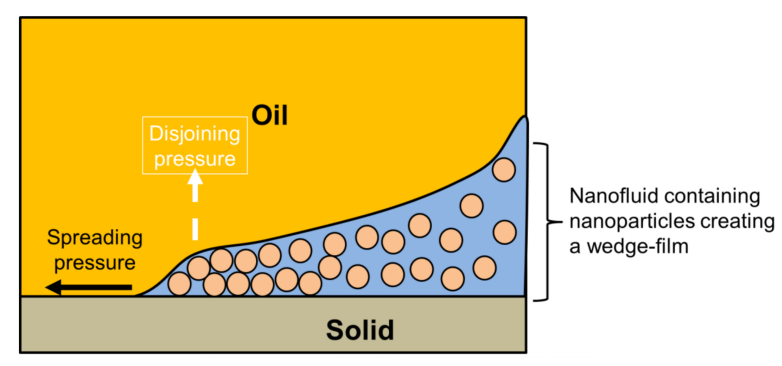

Figure 7. Sketch showing nanoparticle structuring into a wedge-film at the oil/solid/nanofluid spreading front (adapted from Wasan et al. [104]).

Other types of nanoparticles, including organic polymers and metals, have also been studied, the latter because of their associated catalytic properties [102], but oxides such as $\mathrm{SiO}_{2}, \mathrm{ZrO}_{2}$, $\mathrm{Al}_{2} \mathrm{O}_{3}$, and $\mathrm{TiO}_{2}$ offer suitable surface chemistry and thermal stability properties that are potentially more appropriate for displacing heavy oil. Titanium dioxide (in both amorphous form and as crystalline anatase), for instance, has been shown to improve heavy oil recovery from sandstone cores (from $49 \%$ recovery using water/brine to $80 \%$ using $0.01 \%$ anatase under equivalent conditions) [107]. Silica nanoparticles have been shown to be very effective in altering the wettability of calcite [108] and sandstone [109] from oil-wet to water-wet, the change being generally deemed to be beneficial for oil recovery under certain conditions, as discussed above. Zirconium oxide nanoparticles have also been shown to be promising for enhancing oil recovery from carbonate [110].

In addition to the mechanisms indicated above (i.e., production of a structural disjoining pressure [111], wettability alteration, and interfacial tension reduction), the comprehensive review by Sun et al. emphasizes that asphaltene precipitation can also be reduced or prevented in the presence of nanoparticles [112].

As alluded to above, heavy oil and bitumen can be upgraded as a result of reactions, such as aquathermolysis, leading to a reduction in viscosity. A further example of this is the demonstration that nickel nanoparticles applied in a CSS process promoted aquathermolysis and improved oil recovery [113], with a variety of other metal particles providing evidence for heavy oil/bitumen viscosity reduction [114]. More detailed discussions of the application of nanoparticles in in situ upgrading and heavy oil recovery are given elsewhere [115-117]. 


\subsection{Additive Requirements for $S A G D$}

The majority of the above discussions relate primarily to the use of additives in traditional steam stimulation processes, which differ significantly from SAGD; in either situation, however, selection of a particular additive or combination of additives very much depends on the functions required for the specific application. As has been described above, various scenarios are possible-from aiding displacement of the oil from reservoir matrix surfaces to emulsifying a proportion of it, or even upgrading it.

Equation (1) provides some insight into the practical factors associated with additive selection. All the additives and mechanisms described so far can conceivably lead to improved SAGD performance and oil production rates. Thus, for example, surfactant additives favoring oil dispersion in water (rather than water dispersion in oil) will ensure that the effective viscosity of the draining fluids is minimized. This can be achieved using water-soluble surfactants or $\mathrm{w} / \mathrm{o}$ demulsification chemicals.

Additives that act to maximize the displacement of entrained oil will thereby open up the reservoir porosity. Thin film spreading agents (TFSAs) offer one approach in which surfactants facilitate oil displacement by a combination of displacement/detergent action and emulsification. These additives are also considered to reduce the residual oil saturation, hence increasing the $\Delta S_{0}$ term in Equation (1). The basis of TFSAs, as proposed and championed by Charles Blair (Magna Corp., Santa Fe, CA, USA) in the late 1970s [118], is the removal of surface films from rock surfaces. Most reservoir minerals in their natural state exhibit hydrophilic characteristics, yet in contact with crude oil the wettability of their surfaces is modified through adsorption of polar species, including asphaltenes and naphthenic acids. TFSAs comprise highly surface-active polymeric species which are believed to act by spreading readily over the surface and displacing the organic contaminants responsible for oil wetting. The molecular compositions of TFSAs are similar to demulsifiers used to resolve crude oil emulsions [119], and it is therefore unsurprising that the two modes of action are similar [120].

If additives are to be deployed on a continuous basis, they should ideally be introduced with the steam, either co-vaporized or possibly dispersed directly into the steam flow. Low volatility surfactants, for example, would fall into the latter category, whereas more volatile, lower molecular weight candidates will be able to form a homogeneous admixture with the steam, and will also co-condense within the cooler parts of the formation. In addition, although it is not necessarily the most efficient approach, squeezing low volatility additives into the near-wellbore region prior to steaming could still allow sufficient carryover into the growing steam chamber.

In the particular case of SAGD, the additives should retain a major proportion of their (surface) activity upon reaching the steam chamber; thereafter, the level of activity retained will depend on the function they are required to fulfill during further propagation of the chamber. Thermal stability is therefore a significant factor governing the selection of suitable additives. In general, most compounds subjected to high temperature and possibly high $\mathrm{pH}$ hydrolytic conditions will be susceptible to some chemical transformation. The key, therefore, is to identify kinetic stability in compounds for which thermodynamic stability may be limited.

Zeidani and Gupta [121] described the criteria for surfactants suitable for SAGD applications as

- Effective at reducing IFT

- Changes the reservoir wettability to water-wet

- Capable of being vaporized under SAGD operational conditions

- Thermally stable under SAGD conditions

- Able to stabilize oil-in-water emulsions

- Fully compatible with formation water

These researchers also suggested that certain nonionic surfactants possess good attributes as candidates for SAGD applications. One such class of surfactants advocated are tertiary acetylenic diols. Laboratory tests demonstrated that the surfactants were able to increase the oil recovery factor by $6-16 \%[121,122]$. 
As suggested, the $\mathrm{pH}$ conditions will play an important part in determining the relative stability of certain compounds. Knowledge of the likely reservoir conditions to which the additives will be exposed would be helpful in this respect. Potentially, an experimental ex situ assessment of these conditions could be made in laboratory tests under appropriate temperature and pressure conditions. Generally, neutral-to-high $\mathrm{pH}$ conditions are preferable as far as hydrolytic stability is concerned, with acidic conditions largely to be avoided. Recognizing this, Srivastava et al. $[123,124]$ targeted steam-volatile chemical additives to enhance oil recovery under SAGD conditions. These materials are claimed to possess advantages over alkali and surfactants in that they are more easily carried throughout the reservoir with steam [125]. These additives react with, and neutralize, indigenous acid species in the oil, generating surface-active molecules which facilitate the formation of $\mathrm{o} / \mathrm{w}$ emulsions that are more efficiently co-produced with the condensed water. Laboratory tests typically showed approximately $13 \%$ increases in cumulative recovery.

There have also been claims of beneficial effects for oil recovery being obtained using other low molecular weight chemical additives not normally considered in the oil recovery context. Intriguingly, Campos and Hernandez found that the introduction of urea $\left(\mathrm{H}_{2} \mathrm{NCONH}_{2}\right)$ in steamflooding reduced oil viscosity [126]. Under hydrothermal conditions, urea is expected to decompose to ammonia and carbon dioxide according to [127]

$$
\left(\mathrm{NH}_{2}\right)_{2} \mathrm{CO}+\mathrm{H}_{2} \mathrm{O} \rightarrow \mathrm{CO}_{2}+2 \mathrm{NH}_{3}
$$

Tests using Hamaca and Cerro Negro bitumen produced a reduction in viscosity of greater than $90 \%$ by the addition of $2 \%$ urea (relative to steam) at $192{ }^{\circ} \mathrm{C}$. In the field, the steam and urea could be mixed at the surface or downhole in the well, or the urea "can be fed to the boiler feed water for making the steam" [126].

In a patent application, urea has also been proposed as a thermal-trigger agent to accelerate communication between injection and production wells in SAGD [128]. It is likely that a pH increase initiated by release of ammonia under the high temperature aqueous conditions (as in Equation (5)) causes ionization of acid groups on exposed bitumen surfaces in the near-wellbore region, resulting in bitumen de-wetting of the hydrophilic sand surfaces and ultimately release of emulsified bitumen droplets.

In a very recent study [129], various additives were co-injected with steam in order to test their impact on SAGD efficiency. The additives tested included surfactants, ionic liquids, biodiesel, high $\mathrm{pH}$ solutions (using sodium metaborate, $\mathrm{NaBO}_{2}$ ) and silica nanoparticles. The results showed that biodiesel leads to increased oil recovery and reduced the steam/oil ratio during gravity-driven flow, but water consumption was increased. Biodiesel, ionic liquids, and silica nanoparticles showed promising results, but further verification is needed.

One particular approach in the above list which makes specific use of colloid and interfacial chemistry takes advantage of the activation of latent emulsifiers in heavy oils, principally carboxylic (naphthenic and fatty) acids. The effects of alkaline flooding have been described by Liu et al. (using $\left.\mathrm{Na}_{2} \mathrm{CO}_{3}\right)$ [130], Dong et al. $\left(\mathrm{Na}_{2} \mathrm{CO}_{3}, \mathrm{NaOH}\right)$ [131] and Pei et al. $\left(\mathrm{Na}_{2} \mathrm{CO}_{3}\right)$ [132] under conditions of low interfacial disturbance. These alkaline agents operate by reducing the bitumen/water interfacial tension to very low values through ionization of interfacial carboxylic acid (HA) groups to carboxylate, $\mathrm{A}^{-}$), as shown schematically in Figure 8. The situation is made more complex due to partitioning as well as ionization of species at the interface. The scheme shown in Figure 8 is an over-simplification as it does not allow for equilibria involving the different sources of hydroxide ions as indicated above, nor the potential role of cations. 


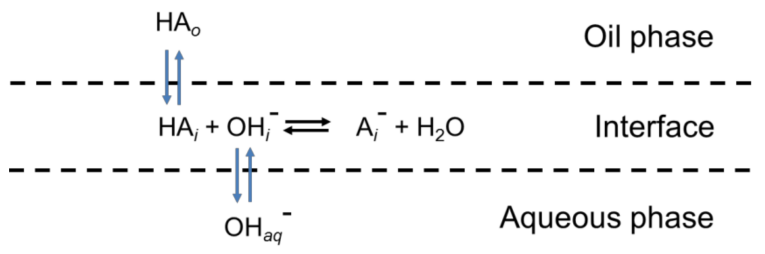

Figure 8. Partitioning of species responsible for interfacial tension reduction at the oil/water interface.

The creation of the negative surface charge (located in the interfacial region in Figure 8) also helps to stabilize bitumen droplets in aqueous media. As indicated above, some recent studies have also used $\mathrm{NaBO}_{2}$ as the alkaline agent [133] which led to $27 \%$ improvement in recovery of a Chinese heavy oil in sandpack tests. Our own work has also considered this alkaline agent as it is more tolerant to divalent metal ions than the corresponding carbonates. Figure 9 shows the effects of varying the $\mathrm{NaBO}_{2}$ concentration on Athabasca bitumen emulsions formed under low intensity agitation in our laboratory. Using higher $\mathrm{NaBO}_{2}$ concentrations produced inferior emulsification, which was identified as being due to the associated higher ionic strength. This is demonstrated in Figure 10 where it can be seen that changing the ionic strength (using $\mathrm{NaCl}$ ) for a constant $\mathrm{NaBO}_{2}$ concentration results in reduced emulsification, indicating the likely role of the electric double layer in stabilizing the emulsions.
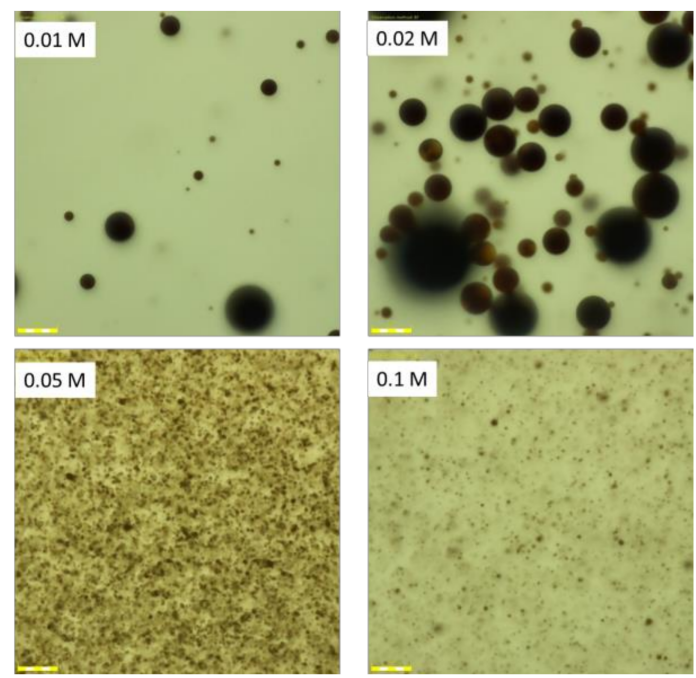

Figure 9. Effect of $\mathrm{NaBO}_{2}$ concentration on low intensity Athabasca bitumen emulsification. The bars represent 50 microns.

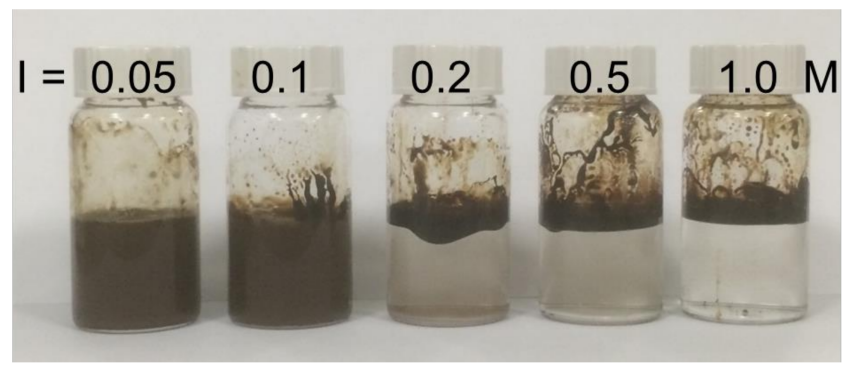

Figure 10. Demonstrating the effect of ionic strength $(\mathrm{NaCl})$ on $0.05 \mathrm{M} \mathrm{NaBO}_{2}$-stabilized Athabasca bitumen-in-water emulsions.

The most common method used for studying steam-based bitumen recovery involves coreflood tests using real core or artificial sandpacks. However, a novel microfluidic approach has recently been 
applied to the examination of the SAGD process, where it was used to evaluate the role of an alkaline steam-based additive in SAGD, which enabled emulsions, both $\mathrm{w} / \mathrm{o}$ and $\mathrm{o} / \mathrm{w}$, formed at the pore-scale to be visualized and quantified [134]. The $\mathrm{o} / \mathrm{w}$ droplet sizes are seen to be significantly reduced in the presence of the additive compared to the baseline pure steam case and the (Cold Lake, $\mathrm{AB}$, Canada) bitumen recovery is increased by $50 \%$. Also interesting was the observation of tighter $\mathrm{w} / \mathrm{o}$ emulsions using additized steam. The formation of $\mathrm{w} / \mathrm{o}$ emulsions of this type has been suggested as being an additional recovery mechanism, perhaps applicable to SAGD, since the resultant expansion of the oil phase could increase the effective contact angle between bitumen and the solid surface [135].

The use of foams has recently been explored by Chen et al. in a process they term foam-assisted SAGD (FA-SAGD) [136]. The proposed process involves co-injection of surfactant solution with steam (continuously or intermittently) to improve the uniform development of steam chambers in heterogeneous reservoirs. As determined by numerical simulation, the results indicated opposing effects of steam foam: on the one hand, the presence of foam impairs gravity drainage and reduces the oil production rate during SAGD plateau production, whereas on the other, improved energy efficiency leads to overall improved performance.

Foams have been used for many years in steam-based recovery processes, and therefore significant experience has been built up in their deployment and selection of foaming agent. To date, however, no experimental FA-SAGD results have been reported to the author's knowledge, but Chen acknowledged that foam stability in the presence of oil is "a potential unknown quantity" [136].

\section{Composition of Produced Water}

From an environmental standpoint, produced water from thermal recovery operations has long been one of the most challenging aspects of heavy oil and bitumen production in which colloidal and interfacial factors play important roles. Not only are high concentrations of dissolved inorganic species (such as silica and other dissolved solids) present as a result of the high steam temperatures, but a considerable amount of small oil droplets (see Figure 3a) and dissolved organic matter can also accumulate. For different reasons, these species cause problems for recycling as boiler feed water (resulting in silicate scale formation) [137] and water disposal (owing to the toxicity of the organic species present) $[52,138,139]$. Control of silicate boiler scale formation is therefore a necessity, which currently employs different softening strategies [140].

Additionally, the existence of mineral fines in the bitumen produced by SAGD has been found to reduce the performance of surfactant-based demulsifiers [141]. Surface-active species from the bitumen adsorb onto the high surface area fines (comprising clays and quartz), making the solids more oil-wet. As a result, adhesion of the solids to the oil droplets is enhanced and the separation of bitumen from water becomes more difficult [141].

Two-dimensional GC-ToFMS analysis has indicated that there is a broad range of dissolved organic compounds in the SAGD produced water, and that the most prevalent constituents among hetero-species (which might possess significant surface activity) include methyl- and ethyl-phenols [142]. Characterization based on FT-ICR high resolution mass spectrometry also showed that the SAGD produced water contains acidic as well as basic species [143]. Razi et al. studied the dynamic interfacial tension between diluted bitumen and SAGD produced water and identified interactions between the polar components in the bitumen and the humic acids in SAGD produced water at basic $\mathrm{pH}(9-10)$ relevant to SAGD operations [144].

Under these process conditions, the effective separation of the different components is essential, and requires appropriate colloid chemical treatment strategies. As detailed in the patent and scientific literature, the use of cationic flocculating agents provides the basis for precipitating solid and bitumen contaminants, which can be removed, for example, using flotation [145] or filtration [146]. A more general review is given by Gupta et al. [147]. 


\section{General Discussion and Conclusions}

The scope of this review has, by necessity, been wide-ranging. It has attempted to apply colloid and interface science concepts to high temperature (steam-based) environments. In so doing, various examples of the use of steam-based additives in thermal recovery processes for heavy oil or bitumen recovery have been identified. When discussing the use of additives in SAGD, for example, it is necessary to consider how they will be introduced into the reservoir, as well as their chemical stability under the relatively harsh hydrothermal conditions.

For the present purposes, the additives have been divided into different classes based on their contributions to different proposed recovery mechanisms. Much of the reported work has been extrapolated from conventional crude oil enhanced oil recovery. Thus, surfactant-based processes utilizing products developed for tertiary recovery of lighter oils have also been directed at heavier oils. Anionic surfactants, usually sulfonates, have been the most common commercial products evaluated. Sulfonates represent the most thermally stable class of anionic surfactants, owing to the stability of the $\mathrm{C}-\mathrm{S}$ bond; in contrast, $\mathrm{C}-\mathrm{O}$ bonds are susceptible to hydrolysis under high temperature aqueous conditions, more typical of steamflooding. Sulfonates are particularly stable at high temperatures under alkaline $\mathrm{pH}$ conditions. Therefore, when used in alkaline surfactant steam floods, for example, sulfonate surfactants should be chemically stable.

As discussed at some length, based on the interfacial chemistry of the reservoir, the principal requirements of additives to enhance hydrocarbon recovery are to increase water wettability and reduce oil/water interfacial tension. To date, transport of additives into the reservoir has been directly via the steam flow, which is particularly applicable to water-soluble species (e.g., [148,149]), although, remarkably, some higher molecular weight surfactants have been advocated as being volatile under SAGD conditions $[121,122]$. More attractive, perhaps, is the potential use of volatile additives that can be co-vaporized with the steam, which would then result in improved uniformity of distribution throughout the formation, e.g., within the steam chamber in SAGD [134,149]. Suitable species for this purpose are generally low molecular weight, with amines, including ammonia being described [125]. In principle, these additives satisfy the two effects mentioned above owing to their ability as bases to activate interfacial surface-active species, thereby reducing interfacial tension and increasing the water wettability of the system [149]. In addition, these additives would direct the formation of the preferred lower viscosity o/w emulsions. In another example [150], co-functionalizing amines with glycol ethers combines basicity with water-wetting properties, although at the expense of volatility.

Only relatively minor attention has been given to the application of nonionic surfactants in heavy oil thermal recovery. However, in a very recent investigation, Sunnatov [151] co-injected the nonionic surfactant Triton X-100 with steam $\left(20{ }^{\circ} \mathrm{C}, 100 \mathrm{psig}\right)$ in horizontal and vertical laboratory test cells. Although the stability of the surfactant was not specifically considered, its addition was shown to produce an average incremental $\left(20^{\circ} \mathrm{API}\right)$ oil recovery of $7 \%$ of the original oil in place compared with steam alone. This suggests that this surfactant survived sufficiently well under the test conditions to produce a positive effect.

As will be apparent from the foregoing, much of the literature that has focused on heavy oil and bitumen thermal recovery has been based on experience derived from conventional enhanced oil recovery. The key differences have been considered throughout the above discussions, but the underlying colloid and interface chemistry principles involved are similar. In the case of the heavier hydrocarbons, however, there is an overriding environmental driver behind attempts to improve recovery. The efficiency of steam-based thermal recovery methods is measured in terms of the steam/oil ratio (SOR) as described in Section 1. The use of additives, whether solvent-based or relying on colloid/interfacial principles, is seen as an important approach to reducing the SOR, thereby improving thermal recovery technology, and in particular SAGD. 
Acknowledgments: This review builds on a heavy oil project initiated in 2012 within the Centre for Petroleum and Surface Chemistry under the original auspices of BP America. Present and past colleagues from that project are thanked for their insight into a technological area that is rich in colloids and interfaces. A special acknowledgement must be given to Huang Zeng, who provided extensive scientific support and stimulating discussions throughout the project. Support from the Department of Chemistry, University of Surrey, enabling continuation of the work, is also acknowledged.

Conflicts of Interest: The author declares no conflicts of interest.

\section{References}

1. Gates, I.D.; Wang, J.Y.J. Evolution of In Situ Oil Sands Recovery Technology in the Field: What Happened and what's New? In SPE Heavy Oil Conference and Exhibition; Society of Petroleum Engineers: Kuwait City, Kuwait, 2011.

2. Gates, I.D.; Chakrabarty, N. Optimization of Steam Assisted Gravity Drainage in McMurray Reservoir. J. Can. Pet. Technol. 2006, 45, 54-62. [CrossRef]

3. Freitag, N.P.; Kristoff, B.J. Comparison of Carbon Dioxide and Methane as Additives at Steamflood Conditions. SPE J. 1998, 3, 14-18. [CrossRef]

4. Speight, J.G. Enhanced Recovery Methods for Heavy Oil and Tar Sands, 1st ed.; Gulf Publishing Company: Houston, TX, USA, 2009; ISBN 978-1-933762-25-8.

5. Holly, C.; Mader, M.; Soni, S.; Toor, J. Alberta Energy Technical Services Alberta Energy: Oil Sands Production Profile 2004-2014; Alberta Provincial Government: Edmonton, AB, Canada, 2016.

6. Alberta Provincial Government Alberta Oil Sands Industry Quarterly Update: Summer 2017. Available online: http:/ / www.albertacanada.com/business/statistics/oil-sands-quarterly.aspx (accessed on 25 March 2018).

7. McCormack, M.E. Design of Steam-Hexane Injection Wells for Gravity Drainage Systems. J. Can. Pet. Technol. 2009, 48, 22-28. [CrossRef]

8. Zajic, J.E.; Cooper, D.G.; Marshall, J.A.; Gerson, D.F. Microstructure of Athabasca Bituminous Sand by Freeze-Fracture Preparation and Transmission Electron Microscopy. Fuel 1981, 60, 619-623. [CrossRef]

9. Takamura, K. Microscopic Structure of Athabasca Oil Sand. Can. J. Chem. Eng. 1982, 60, 538-545. [CrossRef]

10. Hall, A.C.; Collins, S.H.; Melrose, J.C. Stability of Aqueous Wetting Films in Athabasca Tar Sands. Soc. Pet. Eng. J. 1983, 23, 249-258. [CrossRef]

11. He, L.; Li, X.; Wu, G.; Lin, F.; Sui, H. Distribution of Saturates, Aromatics, Resins, and Asphaltenes Fractions in the Bituminous Layer of Athabasca Oil Sands. Energy Fuels 2013, 27, 4677-4683. [CrossRef]

12. Montgomery, W.; Sephton, M.; Watson, J.; Zeng, H. The Effects of Minerals on Heavy Oil and Bitumen Chemistry When Recovered Using Steam-assisted Methods. In Proceedings of the SPE Heavy Oil Conference-Canada, Calgary, AB, Canada, 10-12 June 2014.

13. Hongfu, F.; Yongjian, L.; Liying, Z.; Xiaofei, Z. The Study on Composition Changes of Heavy Oils during Steam Stimulation Processes. Fuel 2002, 81, 1733-1738. [CrossRef]

14. Fan, H.-F.; Liu, Y.-J.; Zhong, L.-G. Studies on the Synergetic Effects of Mineral and Steam on the Composition Changes of Heavy Oils. Energy Fuels 2001, 15, 1475-1479. [CrossRef]

15. Clark, P.; Hyne, J. Steam-Oil Chemical Reactions; Mechanisms for the Aquathermolysis of Heavy Oils. AOSTRA J. Res. 1984, 1, 15-20.

16. Montgomery, W.; Court, R.W.; Rees, A.C.; Sephton, M.A. High Temperature Reactions of Water with Heavy Oil and Bitumen: Insights into Aquathermolysis Chemistry during Steam-Assisted Recovery. Fuel 2013, 113, 426-434. [CrossRef]

17. Jia, N.; Zhao, H.; Yang, T.; Ibatullin, T.; Gao, J. Experimental Measurements of Bitumen-Water Aquathermolysis during a Steam-Injection Process. Energy Fuels 2016, 30, 5291-5299. [CrossRef]

18. Mohammadmoradi, P.; Taheri, S.; Kantzas, A. Interfacial Areas in Athabasca Oil Sands. Energy Fuels 2017, 31 , 8131-8145. [CrossRef]

19. Wiehe, I.A.; Yarranton, H.W.; Akbarzadeh, K.; Rahimi, P.M.; Teclemariam, A. The Paradox of Asphaltene Precipitation with Normal Paraffins. Energy Fuels 2005, 19, 1261-1267. [CrossRef]

20. Acevedo, S.; Ranaudo, M.A.; García, C.; Castillo, J.; Fernández, A. Adsorption of Asphaltenes at the Toluene-Silica Interface: A Kinetic Study. Energy Fuels 2003, 17, 257-261. [CrossRef] 
21. Montoya, T.; Coral, D.; Franco, C.A.; Nassar, N.N.; Cortés, F.B. A Novel Solid-Liquid Equilibrium Model for Describing the Adsorption of Associating Asphaltene Molecules onto Solid Surfaces Based on the "Chemical Theory". Energy Fuels 2014, 28, 4963-4975. [CrossRef]

22. Wang, S.; Liu, Q.; Tan, X.; Xu, C.; Gray, M.R. Adsorption of Asphaltenes on Kaolinite as an Irreversible Process. Colloids Surfaces A: Physicochem. Eng. Aspects 2016, 504, 280-286. [CrossRef]

23. Tsiamis, A.; Taylor, S.E. Adsorption Behavior of Asphaltenes and Resins on Kaolinite. Energy Fuels 2017, 31 , 10576-10587. [CrossRef]

24. Rane, J.P.; Harbottle, D.; Pauchard, V.; Couzis, A.; Banerjee, S. Adsorption Kinetics of Asphaltenes at the Oil-Water Interface and Nanoaggregation in the Bulk. Langmuir 2012, 28, 9986-9995. [CrossRef] [PubMed]

25. Acevedo, S.; Borges, B.; Quintero, F.; Piscitelly, V.; Gutierrez, L.B. Asphaltenes and Other Natural Surfactants from Cerro Negro Crude Oil. Stepwise Adsorption at the Water/Toluene Interface: Film Formation and Hydrophobic Effects. Energy Fuels 2005, 19, 1948-1953. [CrossRef]

26. Kilpatrick, P.K. Water-in-Crude Oil Emulsion Stabilization: Review and Unanswered Questions. Energy Fuels 2012, 26, 4017-4026. [CrossRef]

27. McLean, J.D.; Kilpatrick, P.K. Effects of Asphaltene Aggregation in Model Heptane-Toluene Mixtures on Stability of Water-in-Oil Emulsions. J. Colloid Interface Sci. 1997, 196, 23-34. [CrossRef] [PubMed]

28. McLean, J.D.; Kilpatrick, P.K. Effects of Asphaltene Solvency on Stability of Water-in-Crude-Oil Emulsions. J. Colloid Interface Sci. 1997, 189, 242-253. [CrossRef]

29. Brient, J.A.; Wessner, P.J.; Doyle, M.N. Naphthenic Acids. Kirk-Othmer Encycl. Chem. Technol. 1995. [CrossRef]

30. Headley, J.V.; McMartin, D.W. A Review of the Occurrence and Fate of Naphthenic Acids in Aquatic Environments. J. Environ. Sci. Health Part A 2004, 39, 1989-2010. [CrossRef]

31. Varadaraj, R.; Brons, C. Molecular Origins of Heavy Crude Oil Interfacial Activity. Part 2: Fundamental Interfacial Properties of Model Naphthenic Acids and Naphthenic Acids Separated from Heavy Crude Oils. Energy Fuels 2007, 21, 199-204. [CrossRef]

32. Smith, D.F.; Schaub, T.M.; Rahimi, P.; Teclemariam, A.; Rodgers, R.P.; Marshall, A.G. Self-Association of Organic Acids in Petroleum and Canadian Bitumen Characterized by Low- and High-Resolution Mass Spectrometry. Energy Fuels 2007, 21, 1309-1316. [CrossRef]

33. Varadaraj, R.; Brons, C. Molecular Origins of Heavy Oil Interfacial Activity. Part 1: Fundamental Interfacial Properties of Asphaltenes Derived from Heavy Crude Oils and Their Correlation to Chemical Composition. Energy Fuels 2007, 21, 195-198. [CrossRef]

34. Wang, X.; Pensini, E.; Liang, Y.; Xu, Z.; Chandra, M.S.; Andersen, S.I.; Abdallah, W.; Buiting, J.J. Fatty Acid-Asphaltene Interactions at Oil/Water Interface. Colloids Surfaces A: Physicochem. Eng. Aspects 2017, 513, 168-177. [CrossRef]

35. Wu, X. Investigating the Stability Mechanism of Water-in-Diluted Bitumen Emulsions through Isolation and Characterization of the Stabilizing Materials at the Interface. Energy Fuels 2003, 17, 179-190. [CrossRef]

36. Stanford, L.A.; Rodgers, R.P.; Marshall, A.G.; Czarnecki, J.; Wu, X.A.; Taylor, S. Detailed Elemental Compositions of Emulsion Interfacial Material versus Parent Oil for Nine Geographically Distinct Light, Medium, and Heavy Crude Oils, Detected by Negative- and Positive-Ion Electrospray Ionization Fourier Transform Ion Cyclotron Resonance Mass Spectrometry. Energy Fuels 2007, 21, 973-981. [CrossRef]

37. Collins, S.H.; Melrose, J.C. Adsorption of Asphaltenes and Water on Reservoir Rock Minerals. In Proceedings of the SPE Oilfield and Geothermal Chemistry Symposium, Denver, CO, USA, 1-3 June 1983; Society of Petroleum Engineers: Denver, CO, USA.

38. Gonzalez, G.; Travalloni-Louvisse, A.M. Adsorption of Asphaltenes and Its Effect on Oil Production. SPE Prod. Facil. 1993, 8, 91-96. [CrossRef]

39. Keleşoğlu, S.; Volden, S.; Kes, M.; Sjöblom, J. Adsorption of Naphthenic Acids onto Mineral Surfaces Studied by Quartz Crystal Microbalance with Dissipation Monitoring (QCM-D). Energy Fuels 2012, 26, 5060-5068. [CrossRef]

40. Madsen, L.; Ida, L. Adsorption of Carboxylic Acids on Reservoir Minerals from Organic and Aqueous Phase. SPE Res. Eval. Eng. 1998, 1, 47-51. [CrossRef]

41. Osacky, M.; Geramian, M.; Ivey, D.G.; Liu, Q.; Etsell, T.H. Mineralogical and Chemical Composition of Petrologic End Members of Alberta Oil Sands. Fuel 2013, 113, 148-157. [CrossRef]

42. Sparks, B.D.; Kotlyar, L.S.; O'Carroll, J.B.; Chung, K.H. Athabasca Oil Sands: Effect of Organic Coated Solids on Bitumen Recovery and Quality. J. Pet. Sci. Eng. 2003, 39, 417-430. [CrossRef] 
43. Kotlyar, L.S.; Sparks, B.D.; Woods, J.R.; Chung, K.H. Solids Associated with the Asphaltene Fraction of Oil Sands Bitumen. Energy Fuels 1999, 13, 346-350. [CrossRef]

44. Guttierez, L.; Pawlik, M. Influence of Humic Acids on Oil Sand Processing. Part I: Detection and Quantification of Humic Acids in Oil Sand Ores and Their Effect on Bitumen Wettability. Int. J. Min. Proc. 2014, 126, 117-125. [CrossRef]

45. Guttierez, L.; Pawlik, M. Influence of Humic Acids on Oil Sand Processing. Part II: Relationship between Bitumen Extraction, Humic Acids Concentration and Power Draw Measurements on Oil Sand Slurries. Int. J. Min. Proc. 2014, 126, 126-135. [CrossRef]

46. Kotlyar, L.S.; Ripmeester, J.A.; Sparks, B.D.; Montgomery, D.S. Characterization of Organic-Rich Solids Fractions Isolated from Athabasca Oil Sand Using a Cold Water Agitation Test. Fuel 1988, 67, 221-226. [CrossRef]

47. Margeson, J.; Hornof, V. Characterization of the Humic-Clay Complex and Its Influence on Bitumen Displacement from Athabasca Oil Sand. J. Can. Pet. Technol. 1989, 28, 57-62. [CrossRef]

48. Majid, A.; Ripmeester, J.A. Isolation and Characterization of Humic Acids from Alberta Oil Sands and Related Materials. Fuel 1990, 69, 1527-1536. [CrossRef]

49. Kupai, M.M.; Yang, F.; Harbottle, D.; Moran, K.; Masliyah, J.; Xu, Z. Characterising Rag-Forming Solids. Can. J. Chem. Eng. 2013, 91, 1395-1401. [CrossRef]

50. Jiang, T.; Hirasaki, G.J.; Miller, C.A.; Ng, S. Effects of Clay Wettability and Process Variables on Separation of Diluted Bitumen Emulsion. Energy Fuels 2011, 25, 545-554. [CrossRef]

51. Marhaba, T. Fluorescence Technique for Rapid Identification of DOM Fractions. J. Environ. Eng. 2000, 126, 145-152. [CrossRef]

52. Thakurta, S.G.; Maiti, A.; Pernitsky, D.J.; Bhattacharjee, S. Dissolved Organic Matter in Steam Assisted Gravity Drainage Boiler Blow-Down Water. Energy Fuels 2013, 27, 3883-3890. [CrossRef]

53. Pillai, R.G.; Yang, N.; Thi, S.; Fatema, J.; Sadrzadeh, M.; Pernitsky, D. Characterization and Comparison of Dissolved Organic Matter Signatures in Steam-Assisted Gravity Drainage Process Water Samples from Athabasca Oil Sands. Energy Fuels 2017, 31, 8363-8373. [CrossRef]

54. Chung, T.; Bae, W.; Lee, J.; Lee, W.; Jung, B. A Review of Practical Experience and Management of the SAGD Process for Oil Sands Development. Energy Sources Part Recovery Util. Environ. Eff. 2011, 34, $219-226$. [CrossRef]

55. Butler, R.M.; Yee, C.T. Progress in the In Situ Recovery of Heavy Oils and Bitumen. J. Can. Pet. Technol. $2002,41$. [CrossRef]

56. Jiang, Q.; Thornton, B.; Houston, J.R.; Spence, S. Review of Thermal Recovery Technologies for the Clearwater and Lower Grand Rapids Formations in the Cold Lake Area in Alberta. J. Can. Pet. Technol. 2010, 49, 2-13. [CrossRef]

57. Al Bahlani, A.M.; Babadagli, T. A Critical Review of the Status of SAGD: Where Are We and What Is Next? In Proceedings of the SPE Western Regional and Pacific Section AAPG Joint Meeting, Bakersfield, CA, USA, 29 March-4 April 2008; Society of Petroleum Engineers: Bakersfield, CA, USA.

58. Gotawala, D.R.; Gates, I.D. Steam Fingering at the Edge of a Steam Chamber in a Heavy Oil Reservoir. Can. J. Chem. Eng. 2008, 86, 1011-1022. [CrossRef]

59. Upreti, S.R.; Lohi, A.; Kapadia, R.A.; El-Haj, R. Vapor Extraction of Heavy Oil and Bitumen: A Review. Energy Fuels 2007, 21, 1562-1574. [CrossRef]

60. Chen, Q. Assessing and Improving Steam-Assisted Gravity Drainage: Reservoir Heterogeneities, Hydraulic Fractures, and Mobility Control Foams. Ph.D. Thesis, Stanford University, Stanford, CA, USA, 2009.

61. Acosta, E. Achieving Sustainable, Optimal SAGD Operations. J. Pet. Technol. 2010, 62, 24-28. [CrossRef]

62. Thimm, H.F. Understanding the Generation of Dissolved Silica in Thermal Projects: Theoretical Progress. J. Can. Pet. Technol. 2008, 47, 22-25. [CrossRef]

63. Bowman, R.W.; Gramms, L.C.; Craycraft, R.R. High-Silica Waters in Steamflood Operations. SPE Prod. Facil. 2000, 15, 123-125. [CrossRef]

64. Barillas, J.L.M.; Dutra, T.V.; Mata, W. Reservoir and Operational Parameters Influence in SAGD Process. J. Pet. Sci. Eng. 2006, 54, 34-42. [CrossRef]

65. Butler, R.M.; McNab, G.S.; Lo, H.Y. Theoretical Studies on the Gravity Drainage of Heavy Oil During In-Situ Steam Heating. Can. J. Chem. Eng. 1981, 59, 455-460. [CrossRef] 
66. Krieger, I.M.; Dougherty, T.J. A Mechanism for Non-Newtonian Flow in Suspensions of Rigid Spheres. Trans. Soc. Rheol. 1959, 3, 137-152. [CrossRef]

67. Mueller, S.; Llewellin, E.W.; Mader, H.M. The Rheology of Suspensions of Solid Particles. Proc. R. Soc. Math. Phys. Eng. Sci. 2010, 466, 1201-1228. [CrossRef]

68. Bennion, D.B.; Chan, M.Y.S.; Sarioglu, G.; Courtnage, D.; Wansleeben, J.; Hirata, T. The In-Situ Formation of Bitumen-Water-Stable Emulsions in Porous Media during Thermal Stimulation. In Proceedings of the SPE International Thermal Operations Symposium, Bakersfield, CA, USA, 8-10 February 1993; Society of Petroleum Engineers: Bakersfield, CA, USA.

69. Sarbar, M.; Livesey, D.B.; Wes, W.; Flock, D.L. The Effect of Chemical Additives on the Stability of Oil-in-Water Emulsion Flow through Porous Media. In Proceedings of the 38th Annual CIM Petroleum Society Technical Meeting, Calgary, AB, Canada, 7-10 June 1987.

70. Bosch, R.; Axcell, E.; Little, V.; Cleary, R.; Wang, S.; Gabel, R.; Moreland, B. A Novel Approach for Resolving Reverse Emulsions in SAGD Production Systems. Can. J. Chem. Eng. 2004, 82, 836-839. [CrossRef]

71. Chung, K.; Butler, A. In Situ Emulsification by the Condensation of Steam in Contact with Bitumen. J. Can. Pet. Technol. 1989, 28, 48-55. [CrossRef]

72. Chen, T.; Yuan, J.Y.; Serres, A.J.; Rancier, D.G. Emulsification of Water into Bitumen in Co-injection Experiments. J. Can. Pet. Technol. 1999, 38. [CrossRef]

73. Bryan, J.; Wang, J.; Kantzas, A. Measurement of Emulsion Flow in Porous Media: Improvements in Heavy Oil Recovery. J. Phys. Conf. Ser. 2009, 147, 012058. [CrossRef]

74. Vittoratos, E. Flow Regimes during Cyclic Steam Stimulation at Cold Lake. J. Can. Pet. Technol. 1991, 30, 82-86. [CrossRef]

75. Wang, D.; Lin, M.; Dong, Z.; Li, L.; Jin, S.; Pan, D.; Yang, Z. Mechanism of High Stability of Water-in-Oil Emulsions at High Temperature. Energy Fuels 2016, 30, 1947-1957. [CrossRef]

76. Glandt, C.A.; Chapman, W.G. Effect of Water Dissolution on Oil Viscosity. SPE Reserv. Eng. 1995, 10, 59-64. [CrossRef]

77. Zirrahi, M.; Hassanzadeh, H.; Abedi, J. Experimental and Modeling Studies of MacKay River Bitumen and Water. J. Pet. Sci. Eng. 2017, 151, 305-310. [CrossRef]

78. Drelich, J.; Leliński, D.; Miller, J.D. Bitumen Spreading and Formation of Thin Bitumen Films at a Water Surface. Colloids Surfaces A: Physicochem. Eng. Asp. 1996, 116, 211-223. [CrossRef]

79. Gonzalez, V.; Taylor, S.E. Physical and Chemical Aspects of "Precursor Films" Spreading on Water from Natural Bitumen. J. Petrol. Sci. Eng. Submitted.

80. Azom, P.; Srinivasan, S. Mechanistic Modeling of Emulsion Formation and Heat Transfer during the Steam-Assisted Gravity Drainage (SAGD) Process. In Proceedings of the SPE Annual Technical Conference and Exhibition, New Orleans, LA, USA, 4-7 October 2009; Society of Petroleum Engineers: New Orleans, LA, USA.

81. Sasaki, K.; Akibayashi, S.; Yazawa, N.; Kaneko, F. Microscopic Visualization with High Resolution Optical-Fiber Scope at Steam Chamber Interface on Initial Stage of SAGD Process. In Proceedings of the SPE/DOE Improved Oil Recovery Symposium, Tulsa, OK, USA, 13-17 April 2002; Society of Petroleum Engineers: Tulsa, OK, USA.

82. Zekri, A.; Shedid, S.; Hassan, A. A Novel Technique for Treating Asphaltene Deposition using Laser Technology. In Proceedings of the SPE Permian Basin Oil and Gas Recovery Conference, Midland, TX, USA, 15-17 May 2001; Society of Petroleum Engineers: Midland, TX, USA.

83. Al-Hadhrami, H.; Blunt, M. Thermally Induced Wettability Alteration to Improve Oil Recovery in Fractured Reservoirs. SPE Reservoir Eval. Eng. 2001, 4, 179-186. [CrossRef]

84. Rao, D. Wettability Effects in Thermal Recovery Operations. SPE Res. Eval. Eng. 1999, 2, 420-430. [CrossRef]

85. Isaacs, E.; Nasr, T.; Babchin, A. Enhanced Oil Recovery by Altering Wettability. U.S. Patent 6,186,232, 13 February 2001.

86. Yuan, J.Y.; Law, D.H.S.; Nasr, T.N. Benefit of Wettability Change near the Production Well in SAGD. In Proceedings of the Canadian International Petroleum Conference, Tulsa, OK, USA, 11-13 June 2002; Petroleum Society of Canada: Tulsa, OK, USA.

87. Flury, C.; Afacan, A.; Tamiz Bakhtiari, M.; Sjoblom, J.; Xu, Z. Effect of Caustic Type on Bitumen Extraction from Canadian Oil Sands. Energy Fuels 2014, 28, 431-438. [CrossRef] 
88. Castanier, L.M.; Brigham, W.E. An Evaluation of Field Projects of Steam with Additives. SPE Res. Eng. 1991, 6, 62-68. [CrossRef]

89. Shedid, S.A.; El Abbas, A.A. Experimental Study of Surfactant Alkaline Steam Flood through Vertical Wells. In Proceedings of the SPE/AAPG Western Regional Meeting, Long Beach, CA, USA, 19-22 June 2000; Society of Petroleum Engineers: Long Beach, CA, USA.

90. El Abbas, A.; Shedid, S. Experimental Investigation of the Feasibility of Steam/Chemical Steam Flooding Processes through Horizontal Wells. In Proceedings of the SPE Asia Pacific Oil and Gas Conference and Exhibition, Jakarta, Indonesia, 17-19 April 2001; Society of Petroleum Engineers: Jakarta, Indonesia.

91. Yamazaki, T.; Matsuzawa, N.; Abdelkarim, O.; Ono, Y. Recovery of Bitumen from Oil Sand by Steam with Chemicals. J. Pet. Sci. Eng. 1989, 3, 147-159. [CrossRef]

92. Madhavan, R.M.; Mamora, D.D. Experimental Investigation of Caustic Steam Injection for Heavy Oils. In Proceedings of the SPE Improved Oil Recovery Symposium, Tulsa, OK, USA, 24-28 April 2010; Society of Petroleum Engineers: Tulsa, OK, USA.

93. Brown, A.; Carlin, J.; Fontaine, M.; Haynes, S. Method for Recovery of Hydrocarbons Utilizing Steam Injection. U.S. Patent 3,732,926, 15 May 1973.

94. Katritzky, A.R.; Allin, S.M.; Siskin, M. Aquathermolysis: Reactions of Organic Compounds with Superheated Water. Acc. Chem. Res. 1996, 29, 399-406. [CrossRef]

95. Gall, J.W. Steam Diversion by Surfactants. In SPE Annual Technical Conference and Exhibition; Society of Petroleum Engineers: Las Vegas, NV, USA, 1985.

96. Dilgren, R.E.; Owens, K.B. Olefin Sulfonate-Improved Steam Foam Drive. U.S. Patent 4,393,937, 19 July 1983.

97. Maini, B.B.; Ma, V. Laboratory Evaluation of Foaming Agents for High-Temperature Applications: I. Measurements of Foam Stability at Elevated Temperatures and Pressures. J. Can. Pet. Technol. 1986, 25. [CrossRef]

98. Novosad, J.; Maini, B.B.; Huang, A. Retention of Foam-Forming Surfactants at Elevated Temperatures. J. Can. Pet. Technol. 1986, 25. [CrossRef]

99. Cheraghian, G.; Hendraningrat, L. A Review on Applications of Nanotechnology in the Enhanced Oil Recovery. Part A: Effects of Nanoparticles on Interfacial Tension. Int. Nano Lett. 2016, 6, 129-138. [CrossRef]

100. Cheraghian, G.; Hendraningrat, L. A Review on Applications of Nanotechnology in the Enhanced Oil Recovery. Part B: Effects of Nanoparticles on Flooding. Int. Nano Lett. 2016, 6, 1-10. [CrossRef]

101. Negin, C.; Ali, S.; Xie, Q. Application of Nanotechnology for Enhancing Oil Recovery-A Review. Petroleum 2016, 2, 324-333. [CrossRef]

102. Hashemi, R.; Nassar, N.N.; Almao, P.P. Nanoparticle Technology for Heavy Oil In-Situ Upgrading and Recovery Enhancement: Opportunities and Challenges. Appl. Energy 2014, 133, 374-387. [CrossRef]

103. Wasan, D.T.; Nikolov, A.D. Spreading of Nanofluids on Solids. Nature 2003, 423, 156-159. [CrossRef] [PubMed]

104. Wasan, D.; Nikolov, A.; Kondiparty, K. The Wetting and Spreading of Nanofluids on Solids: Role of the Structural Disjoining Pressure. Curr. Opin. Colloid Interface Sci. 2011, 16, 344-349. [CrossRef]

105. Lim, S.; Horiuchi, H.; Nikolov, A.D.; Wasan, D. Nanofluids Alter the Surface Wettability of Solids. Langmuir 2015, 31, 5827-5835. [CrossRef] [PubMed]

106. Wu, S.; Nikolov, A.; Wasan, D. Cleansing Dynamics of Oily Soil using Nanofluids. J. Colloid Interface Sci. 2013, 396, 293-306. [CrossRef] [PubMed]

107. Ehtesabi, H.; Ahadian, M.M.; Taghikhani, V.; Ghazanfari, M.H. Enhanced Heavy Oil Recovery in Sandstone Cores Using $\mathrm{TiO}_{2}$ Nanofluids. Energy Fuels 2013, 28, 423-430. [CrossRef]

108. Al-Anssari, S.; Arif, M.; Wang, S.; Barifcani, A.; Lebedev, M.; Iglauer, S. Wettability of Nanofluid-Modified Oil-Wet Calcite at Reservoir Conditions. Fuel 2018, 211, 405-414. [CrossRef]

109. Huibers, B.M.J.; Pales, A.R.; Bai, L.; Li, C.; Mu, L.; Ladner, D.; Daigle, H.; Darnault, C.J.G. Wettability Alteration of Sandstones by Silica Nanoparticle Dispersions in Light and Heavy Crude Oil. J. Nanopart. Res. 2017, 19, 323. [CrossRef]

110. Wei, Y.; Babadagli, T. Selection of Proper Chemicals to Improve the Performance of Steam Based Thermal Applications in Sands and Carbonates. In Proceedings of the SPE Latin America and Caribbean Heavy and Extra Heavy Oil Conference, Lima, Peru, 19-20 October 2016; Society of Petroleum Engineers: Lima, Peru.

111. Zhang, H.; Nikolov, A.; Wasan, D. Enhanced Oil Recovery (EOR) Using Nanoparticle Dispersions: Underlying Mechanism and Imbibition Experiments. Energy Fuels 2014, 28, 3002-3009. [CrossRef] 
112. Sun, X.; Zhang, Y.; Chen, G.; Gai, Z. Application of Nanoparticles in Enhanced Oil Recovery: A Critical Review of Recent Progress. Energies 2017, 10, 345. [CrossRef]

113. Shokrlu, Y.H.; Babadagli, T. In-Situ Upgrading of Heavy Oil/Bitumen during Steam Injection by Use of Metal Nanoparticles: A Study on In-Situ Catalysis and Catalyst Transportation. SPE Res. Eval. Eng. 2013, 16, 333-344. [CrossRef]

114. Shokrlu, Y.H.; Babadagli, T. Viscosity Reduction of Heavy Oil/Bitumen using Micro- and Nano-Metal Particles during Aqueous and Non-Aqueous Thermal Applications. J. Petrol. Sci. Eng. 2014, 119, 210-220. [CrossRef]

115. Guo, K.; Li, H.; Yu, Z. Metallic Nanoparticles for Enhanced Heavy Oil Recovery: Promises and Challenges. Energy Procedia 2015, 75, 2068-2073. [CrossRef]

116. Hashemi, R.; Nassar, N.N.; Almao, P.P. Enhanced Heavy Oil Recovery by in Situ Prepared Ultradispersed Multimetallic Nanoparticles: A Study of Hot Fluid Flooding for Athabasca Bitumen Recovery. Energy Fuels 2013, 27, 2194-2201. [CrossRef]

117. Hashemi, R.; Nassar, N.N.; Almao, P.P. In Situ Upgrading of Athabasca Bitumen Using Multimetallic Ultradispersed Nanocatalysts in an Oil Sands Packed-Bed Column: Part 1. Produced Liquid Quality Enhancement. Energy Fuels 2014, 28, 1338-1350. [CrossRef]

118. Blair, C.M. Method of Recovering Petroleum from a Subterranean Reservoir Incorporating Resinous Polyalkylene Oxide Adducts. U.S. Patent 4,260,019, 7 April 1981.

119. Taylor, S.E. Resolving Crude Oil Emulsions. Chem. Ind. 1992, 20, 770-773.

120. Blair, C.M.; Scribner, R.E.; Stout, C.A. Persistent Action of Thin-Film Spreading Agents used in Cyclic Steam Stimulation. In Proceedings of the SPE California Regional Meeting, Ventura, CA, USA, 23-25 March 1983; Society of Petroleum Engineers: Ventura, CA, USA.

121. Zeidani, K.; Gupta, S. Hydrocarbon Recovery from Bituminous Sands with Injection of Surfactant Vapour. U.S. Patent Application 2013/0081808, 4 April 2013.

122. Zeidani, K.; Gupta, S.C. Surfactant-Steam Process: An Innovative Enhanced Heavy Oil Recovery Method for Thermal Applications. In Proceedings of the SPE Heavy Oil Conference Canada, Calgary, AB, Canada, 11-13 June 2013; Society of Petroleum Engineers: Calgary, AB, Canada.

123. Srivastava, P.; Debord, J.; Sadetsky, V.; Stefan, B.J.; Orr, B.W. Laboratory Evaluation of a Chemical Additive to Increase Production in Steam Assisted Gravity Drainage (SAGD). In Proceedings of the SPE Improved Oil Recovery Symposium, Tulsa, OK, USA, 24-28 April 2010; Society of Petroleum Engineers: Tulsa, OK, USA.

124. Srivastava, P.; Sadetsky, V.; Debord, J.; Stefan, B.; Orr, B. Development of a Steam-Additive Technology to Enhance Thermal Recovery of Heavy Oil. In Proceedings of the SPE Annual Technical Conference, Florence, Italy, 19-22 September 2010; Society of Petroleum Engineers: Florence, Italy.

125. Hart, P.R.; Stefan, B.J.; Srivastava, P.; Debord, J.D. Method for Enhancing Heavy Hydrocarbon Recovery. U.S. Patent 7,938,183, 11 May 2011.

126. Campos, R.E.; Hernandez, J.A. In-Situ Reduction of Oil Viscosity during Steam Injection Process in EOR. U.S. Patent 5,314,615, 24 May 1994.

127. Koebel, M.; Strutz, E.O. Thermal and Hydrolytic Decomposition of Urea for Automotive Selective Catalytic Reduction Systems: Thermochemical and Practical Aspects. Ind. Eng. Chem. Res. 2003, 42, 2093-2100. [CrossRef]

128. Rees, A.C.; Coulter, C.; Engelman, R.; Guerrero-Aconcha, U.; Taylor, S.E.; Peats, A.; Zeng, H. Systems and Methods for Accelerating Production of Viscous Hydrocarbons in a Subterranean Reservoir with Thermally Activated Chemical Agents. U.S. Patent Application 2014/0262241, 18 September 2014.

129. Bruns, F; Babadagli, T. Recovery Improvement of Gravity Driven Steam Applications Using New Generation Chemical Additives. In Proceedings of the SPE Western Regional Meeting, Bakersfield, CA, USA, 23-27 April 2017; Society of Petroleum Engineers: Bakersfield, CA, USA.

130. Liu, Q.; Dong, M.; Yue, X.; Hou, J. Synergy of Alkali and Surfactant in Emulsification of Heavy Oil in Brine. Colloids Surfaces A Physicochem. Eng. Asp. 2006, 273, 219-228. [CrossRef]

131. Dong, M.; Ma, S.; Liu, Q. Enhanced Heavy Oil Recovery through Interfacial Instability: A Study of Chemical Flooding for Brintnell Heavy Oil. Fuel 2009, 88, 1049-1056. [CrossRef]

132. Pei, H.; Zhang, G.; Ge, J.; Jin, L.; Ding, L. Study on the Variation of Dynamic Interfacial Tension in the Process of Alkaline Flooding for Heavy Oil. Fuel 2013, 104, 372-378. [CrossRef] 
133. Tang, M.; Zhang, G.; Ge, J.; Jiang, P.; Liu, Q.; Pei, H.; Chen, L. Investigation into the Mechanisms of Heavy Oil Recovery by Novel Alkaline Flooding. Colloids Surfaces A Physicochem. Eng. Asp. 2006, 421, 91-100. [CrossRef]

134. De Haas, T.W.; Fadaei, H.; Guerrero, U.; Sinton, D. Steam-on-a-Chip for Oil Recovery: The Role of Alkaline Additives in Steam Assisted Gravity Drainage. Lab. Chip 2013, 13, 3832. [CrossRef] [PubMed]

135. Gonzalez, V.; Jones, M.; Taylor, S.E. Spin-Spin Relaxation Time Investigation of Oil/Brine/Sand Systems. Kinetics, Effects of Salinity, and Implications for Wettability and Bitumen Recovery. Energy Fuels 2016, 30, 844-853. [CrossRef]

136. Chen, Q.; Gerritsen, M.G.; Kovscek, A.R. Improving Steam-Assisted Gravity Drainage Using Mobility Control Foams: Foam Assisted-SAGD (FA-SAGD). In Proceedings of the SPE Improved Oil Recovery Symposium, Tulsa, OK, USA, 24-28 April 2010; Society of Petroleum Engineers: Tulsa, OK, USA.

137. Maiti, A.; Sadrezadeh, M.; Thakurta, S.G.; Pernitsky, D.J.; Bhattacharjee, S. Characterization of Boiler Blowdown Water from Steam-Assisted Gravity Drainage and Silica-Organic Coprecipitation during Acidification and Ultrafiltration. Energy Fuels 2012, 26, 5604-5612. [CrossRef]

138. Clemente, J.S.; Fedorak, P.M. A Review of the Occurrence, Analyses, Toxicity, and Biodegradation of Naphthenic Acids. Chemosphere 2005, 60, 585-600. [CrossRef] [PubMed]

139. Kawaguchi, H.; Li, Z.; Masuda, Y.; Sato, K.; Nakagawa, H. Dissolved Organic Compounds in Reused Process Water for Steam-Assisted Gravity Drainage Oil Sands Extraction. Water Res. 2012, 46, 5566-5574. [CrossRef] [PubMed]

140. Xu, Y.; Dong, B.; Dai, X. Effect of the Silica-Rich, Oilfield-Produced Water with Different Degrees of Softening on Characteristics of Scales in Steam-Injection Boiler. Desalination 2015, 361, 38-45. [CrossRef]

141. Angle, C.W.; Dabros, T.; Hamza, H.A. Demulsifier Effectiveness in Treating Heavy Oil Emulsion in the Presence of Fine Sands in the Production Fluids. Energy Fuels 2007, 21, 912-919. [CrossRef]

142. Petersen, M.A.; Grade, H. Analysis of Steam Assisted Gravity Drainage Produced Water using Two-Dimensional Gas Chromatography with Time-of-Flight Mass Spectrometry. Ind. Eng. Chem. Res. 2011, 50, 12217-12224. [CrossRef]

143. Lewis, A.T.; Tekavec, T.N.; Jarvis, J.M.; Juyal, P.; McKenna, A.M.; Yen, A.T.; Rodgers, R.P. Evaluation of the Extraction Method and Characterization of Water-Soluble Organics from Produced Water by Fourier Transform Ion Cyclotron Resonance Mass Spectrometry. Energy Fuels 2013, 27, 1846-1855. [CrossRef]

144. Razi, M.; Sinha, S.; Waghmare, P.R.; Das, S.; Thundat, T. Effect of Steam-Assisted Gravity Drainage Produced Water Properties on Oil/Water Transient Interfacial Tension. Energy Fuels 2016, 30, 10714-10720. [CrossRef]

145. Sikes, C.S.; Sikes, D.; Hochwalt, M.A. Flotation and Separation of Flocculated Oils and Solids from Waste Waters. U.S. Patent 9,321,663, 26 April 2016.

146. Alpatova, A.; Kim, E.-S.; Dong, S.; Sun, N.; Chelme-Ayala, P.; El-Din, M.G. Treatment of Oil Sands Process-Affected Water with Ceramic Ultrafiltration Membrane: Effects of Operating Conditions on Membrane Performance. Sep. Purific. Technol. 2014, 122, 170-182. [CrossRef]

147. Gupta, R.K.; Dunderdale, G.J.; England, M.W.; Hozumi, A. Oil/Water Separation Techniques: A Review of Recent Progresses and Future Directions. J. Mater. Chem. A 2017, 5, 16025-16058. [CrossRef]

148. Cross, K.J. Additives for Improving Hydrocarbon Recovery. U.S. Patent Application 2012/0312532, 12 December 2012.

149. Guerrero, U. In Situ Hydrocarbon Recovery Operations such as SAGD with Injection of Water-Wetting Agents. WO Patent Application 2015/061903, 7 May 2015.

150. Ayika, A.A.; Donate, F.A. Method to Extract Bitumen from Oil Sands. U.S. Patent Application 2015/0307787, 29 October 2015.

151. Sunnatov, D.M. Experimental Study of Steam Surfactant Flood. Master's Thesis, Texas A\&M University, College Station, TX, USA, 2010.

(C) 2018 by the author. Licensee MDPI, Basel, Switzerland. This article is an open access article distributed under the terms and conditions of the Creative Commons Attribution (CC BY) license (http://creativecommons.org/licenses/by/4.0/). 